\title{
A DOCK8-WIP-WASp complex links T cell receptors to the actin cytoskeleton
}

\author{
Erin Janssen, ${ }^{1}$ Mira Tohme, ${ }^{1}$ Mona Hedayat, ${ }^{1}$ Marion Leick, ${ }^{2}$ Sudha Kumari, ${ }^{3}$ Narayanaswamy Ramesh, ${ }^{1}$ Michel J. Massaad, ${ }^{1}$ \\ Sumana Ullas, ${ }^{1}$ Veronica Azcutia, ${ }^{2}$ Christopher C. Goodnow, ${ }^{4}$ Katrina L. Randall, ${ }^{5}$ Qi Qiao, ${ }^{6}$ Hao Wu, ${ }^{6}$ Waleed Al-Herz, ${ }^{7}$ \\ Dianne Cox, ${ }^{8}$ John Hartwig, ${ }^{9}$ Darrell J. Irvine, ${ }^{3}$ Francis W. Luscinskas, ${ }^{2}$ and Raif S. Geha ${ }^{1}$
}

\begin{abstract}
'Division of Immunology, Boston Children's Hospital, Department of Pediatrics, Harvard Medical School, Boston, Massachusetts, USA. ²enter for Excellence in Vascular Biology, Brigham and Women's Hospital, Department of Pathology, Harvard Medical School, Boston, Massachusetts, USA. 3 Department of Bioengineering and Koch Institute of Integrative Cancer Research, Massachusetts Institute of Technology, Cambridge, Massachusetts, USA. ${ }^{4}$ John Curtin School of Medical Research, Australian National University, Canberra, Australia. ${ }^{5} \mathrm{ANU}$ Medical School, Australian National University, Canberra, Australia. ${ }^{6}$ Department of Biological Chemistry and Molecular Pharmacology, Harvard Medical School, Program in Cellular and Molecular Medicine, Boston Children's Hospital, Boston, Massachusetts, USA. ${ }^{7}$ Department of Pediatrics, Faculty of Medicine, Kuwait University and Allergy and Clinical Immunology Unit, Al-Sabah Hospital, Kuwait. ${ }^{8}$ Department of Anatomy and Structural Biology, Albert Einstein College of Medicine, New York, New York, USA. 'Division of Translational Medicine, Brigham and Women's Hospital, Boston, Massachusetts, USA
\end{abstract}

\begin{abstract}
Wiskott-Aldrich syndrome (WAS) is associated with mutations in the WAS protein (WASp), which plays a critical role in the initiation of T cell receptor-driven (TCR-driven) actin polymerization. The clinical phenotype of WAS includes susceptibility to infection, allergy, autoimmunity, and malignancy and overlaps with the symptoms of dedicator of cytokinesis 8 (DOCK8) deficiency, suggesting that the 2 syndromes share common pathogenic mechanisms. Here, we demonstrated that the WASpinteracting protein (WIP) bridges DOCK8 to WASp and actin in T cells. We determined that the guanine nucleotide exchange factor activity of DOCK8 is essential for the integrity of the subcortical actin cytoskeleton as well as for TCR-driven WASp activation, F-actin assembly, immune synapse formation, actin foci formation, mechanotransduction, $T$ cell transendothelial migration, and homing to lymph nodes, all of which also depend on WASp. These results indicate that DOCK8 and WASp are in the same signaling pathway that links TCRs to the actin cytoskeleton in TCR-driven actin assembly. Further, they provide an explanation for similarities in the clinical phenotypes of WAS and DOCK8 deficiency.
\end{abstract}

\section{Introduction}

The integrity of the actin cytoskeleton is important for $\mathrm{T}$ cell migration into tissues, defense against pathogens, and immunosurveillance (1). The Wiskott-Aldrich syndrome (WAS) protein WASp plays an important role in the organization and function of the actin cytoskeleton in hematopoietic cells (2). WASp and its homolog neuronal WASp (N-WASp) are important activators of the actin-related protein $2 / 3$ (ARP2/3) complex, which initiates actin polymerization (2). In resting cells, WASp exists in a closed, inactive conformation due to intramolecular interactions that prevent the $\mathrm{C}$-terminal acidic domain from interacting with the ARP2/3 complex. The small Rho GTPase cell division cycle 42 (CDC42) is an important activator of WASp (3). Binding of CDC42-GTP to the GTPase-binding domain (GBD) of WASp causes a conformational change, which allows WASp to interact with and activate the ARP2/3 complex $(4,5)$. T cells deficient in WASp have low baseline F-actin levels, impaired T cell receptordriven (TCR-driven) actin assembly, immune synapse (IS) formation, actin foci formation and mechanotransduction, and defective migration into tissues $(2,6)$.

Authorship note: E. Janssen, M. Tohme, M. Hedayat, and M. Leick are co-first authors. F.W. Luscinskas and R.S. Geha are co-senior authors.

Conflict of interest: The authors have declared that no conflict of interest exists. Submitted: December 1, 2015; Accepted: July 28, 2016.

Reference information: / Clin Invest. 2016;126(10):3837-3851. doi:10.1172/JCI85774
WASp is complexed with the WASp-interacting protein (WIP), which is essential for WASp stability (2). WIP also binds to actin (2). T cells from WIP-deficient mice and knockin mice expressing a WIP mutant that fails to bind actin exhibit cytoskeletal and functional defects similar to, but more severe than, those of WASpdeficient $\mathrm{T}$ cells (7), suggesting that WIP can regulate the $\mathrm{T}$ cell actin cytoskeleton independently of WASp.

Dedicator of cytokinesis 8 (DOCK8) is one of the eleven members of the DOCK180 superfamily (8). DOCK proteins have characteristic DOCK homology region 1 and 2 (DHR1 and DHR2) domains. The DHR1 domain is important for targeting DOCK proteins to membranes, through its binding of phosphatidylinositol $(3,4,5)$-triphosphate $\left(\mathrm{PIP}_{3}\right)$. The DHR2 domain binds to and functions as a GEF for CDC42 (9). Several observations suggest that DOCK8 regulates actin cytoskeleton-dependent functions. DOCK8-deficient B cells, T cells, and NK cells have defective IS formation (10-12), and DOCK8-deficient DCs have defective migration in vivo and in vitro in a 3D collagen gel matrix (13).

WASp deficiency, which results in the X-linked WAS, and DOCK8 deficiency, which causes autosomal recessive hyper IgE syndrome, share clinical and laboratory findings that include recurrent sinopulmonary infections, viral skin infections, eczema, elevated serum IgE levels, food allergies, and an increased risk for malignancy and autoimmune diseases (14-16). Moreover, DOCK8 is a GEF for the WASp activator CDC42 (17), and DOCK8 and WASp exist in a complex in a human NK cell line (18). We show here that 
A

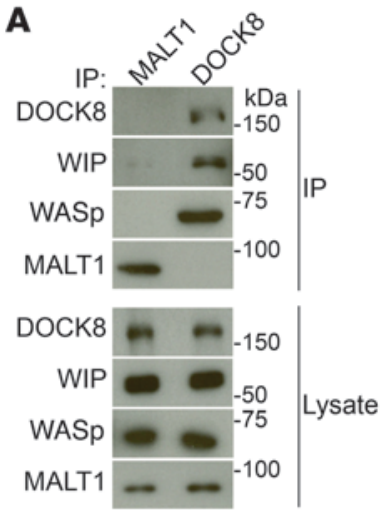

D

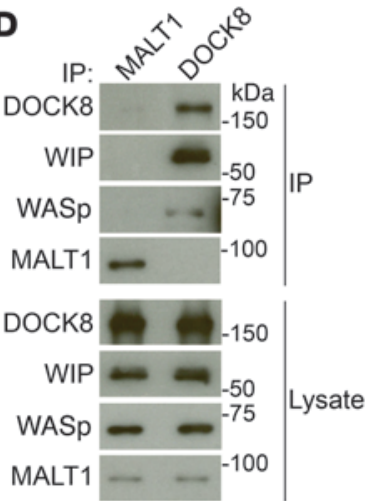

B

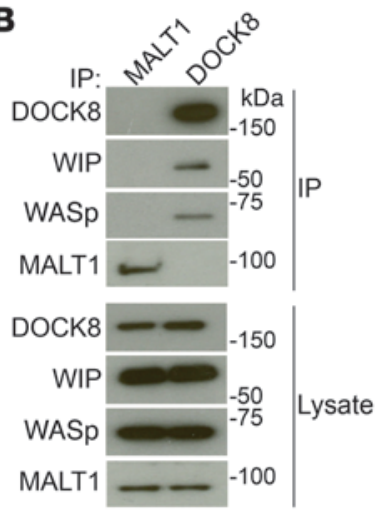

E
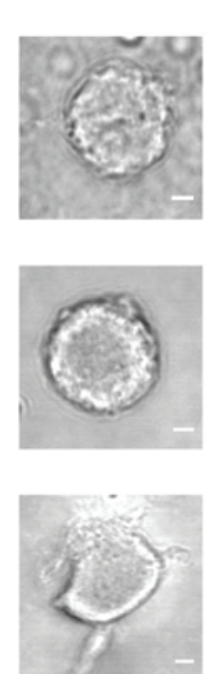

C

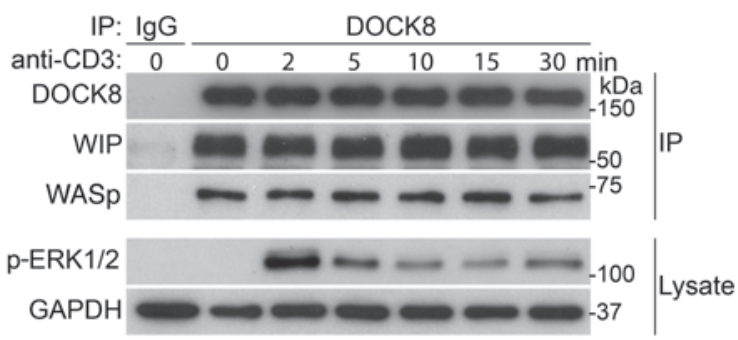

WIP
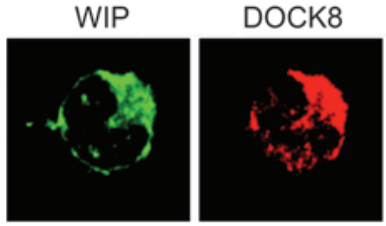

Merge

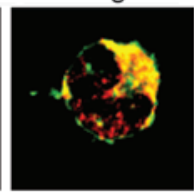

WASp

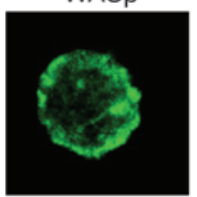

WASp

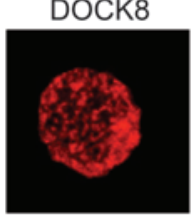

Merge

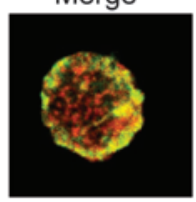

WIP
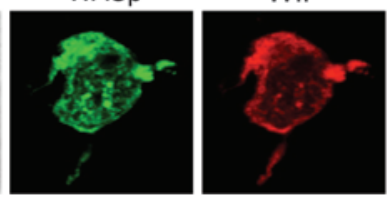

Merge

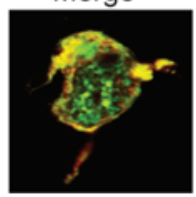

Figure 1. DOCK8 interacts constitutively and colocalizes with WASp and WIP in T cells. (A and B) Co-IP of WIP and WASp with DOCK8, but not MALT1, in human peripheral blood T cells (A) and mouse splenic T cells (B). Aliquots from the lysates used for IP were probed with DOCK8, WASp, WIP, and MALT1 to ensure equal loading. (C) Lack of a detectable effect of TCR ligation with anti-CD3 mAb on the association of DOCK8 with WIP and WASp in human blood T cells. Lysates were probed with a phospho-specific ERK1/ERK2 (p-ERK1/2) Ab to verify TCR signaling and with GAPDH as a loading control. IP with an IgG isotype Ab was used as a negative control. (D) Co-IP of WIP and WASp with DOCK8, but not MALT1, in the human DND41 T cell line. (E) Colocalization of WIP and WASp with DOCK8. Representative DIC images (left), confocal immunofluorescence microscopic images (middle), and merged images (right) of DND41 T cells permeabilized and stained with Abs against DOCK8, WIP, and WASp, followed by fluorochrome-labeled secondary Abs. Original magnification, $\times 63$. Scale bars: $2 \mu \mathrm{m}$. Data in A-D represent 3 independent experiments each. Images in $\mathbf{E}$ are representative of 50 cells that were examined in 2 independent experiments.

WIP bridges DOCK8 to WASp and actin and that DOCK8, and in particular DOCK8 GEF activity, is essential for TCR-driven WASp activation and F-actin assembly, the integrity of the subcortical actin cytoskeleton, TCR-driven actin foci formation and mechanotransduction, and transendothelial migration (TEM) of T cells, all of which also depend on WASp. These findings provide a molecular explanation for the shared features of DOCK8 deficiency and WAS.

\section{Results}

DOCK8 binds to and colocalizes constitutively with WIP and WASp in T cells. We examined whether DOCK8 interacts with WASp and WIP in primary $\mathrm{T}$ cells. Lysates from $\mathrm{CD} 3^{+} \mathrm{T}$ cells purified from human blood and mouse spleens were immunoprecipitated with rabbit anti-DOCK8 polyclonal Ab, or rabbit anti-MALT1 polyclonal Ab as a negative control, and the immunoprecipitates were probed for DOCK8, WASp, and WIP. Immunoblot analysis demonstrated the presence of WASp and WIP in DOCK8, but not MALT1, immuno- precipitates (Figure 1, A and B). These results indicate that DOCK8 constitutively associates with WASp and WIP in primary T cells.

TCR ligation induces tyrosine phosphorylation of DOCK8, WASp, and WIP $(19,20)$. Ligation of the TCR complex in human $\mathrm{T}$ cells with anti-CD3 $\mathrm{mAb}$ had no detectable effect on the association of DOCK8 with WASp or WIP (Figure 1C) but caused robust ERK phosphorylation, demonstrating effective TCR signaling. Similar results were obtained with mouse splenic $\mathrm{T}$ cells (data not shown). These results indicate that TCR signaling does not alter the constitutive association of DOCK8 with WASp and WIP.

The subcellular localization of DOCK8, WASp, and WIP in T cells was examined in the human $\mathrm{T}$ cell acute lymphoblastic leukemia (T-ALL) lymphoblast cell line DND41, which has a relatively abundant cytoplasm compared with that of primary resting $\mathrm{T}$ cells. As in primary T cells, WASp and WIP coimmunoprecipitated with DOCK8 from DND41 cell lysates (Figure 1D). Intracellular immunofluorescence revealed that DOCK8 colocalized with both WIP and 
A

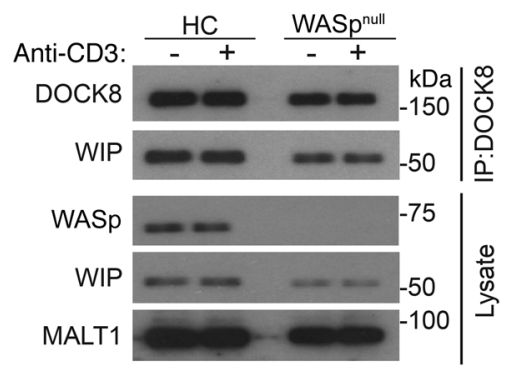

C
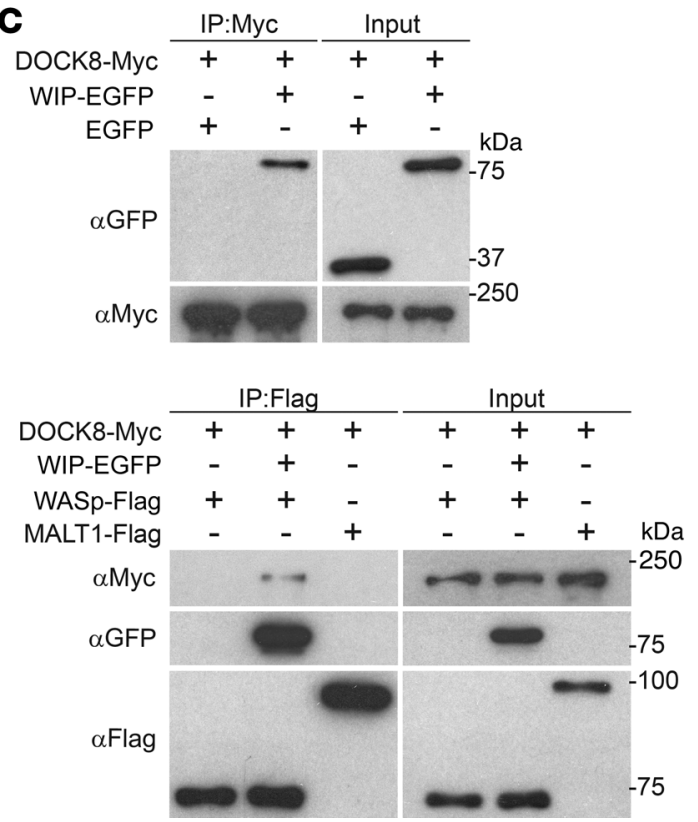

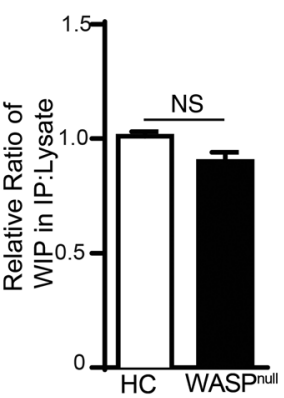

B
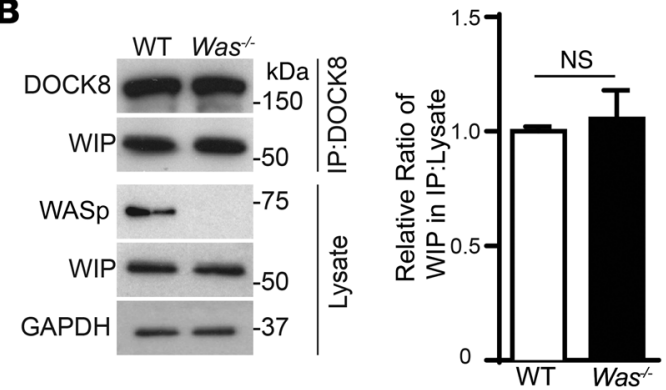

Figure 2. WIP bridges DOCK8 to WASp. (A and B) Representative immunoblot and quantitative analysis of co-IP of WIP and DOCK8 from peripheral blood T cell lysates from an $\mathrm{HC}$ and a WASp ${ }^{\text {null }}$ patient $(\mathbf{A})$ and of mouse splenic T cells from WT and Was ${ }^{-/-}$mice (B). T cells were examined 0 and 10 minutes after (+) anti-CD3 stimulation. Using densitometric scanning, quantification of the results was performed by calculating the ratio of WIP/DOCK8 bands in the DOCK8 immunoprecipitates to that in the lysates relative to controls. The results in A represent 2 WAS patients and 2 controls examined in 2 independent experiments, and in B, 3 WT and $3 \mathrm{Was}^{-/-}$mice were examined in 3 independent experiments. Aliquots from the lysates used for IP were probed with MALT1 in A and with GAPDH in B to ensure equal loading. Error bars in A and B represent the mean \pm SEM. Student's $t$ test. (C) Co-IP of rWIP-EGFP, but not EGFP, with rMyc-tagged DOCK8 (DOCK8-Myc) proteins (top panel) and of rDOCK8-Myc with rWASp-Flag, but not rMALT1-Flag, in the presence, but not in the absence, of rWIP-EGFP (bottom panel). (D) Map of the WIPAWBD protein. (E) Representative immunoblot of the co-IP of WIP-EGFP and WIPAWBD-EGFP with Myc-tagged DOCK8 in 293T cell transfectants. LRRC8A-Myc and EGFP transfectants were used as negative controls, and lysate aliquots were probed for Myc and EGFP to ensure equal loading. The * denotes a non-specific band. (F) Co-IP of DOCK8 and WASp with WIP in human T cells, using the 3010 and D12C5 anti-WIP mAbs directed against distinct epitopes in the N-terminus and C-terminus of WIP, respectively. Data in C, E, and F represent 4 independent experiments.

WASp (Figure 1E). As expected, WASp and WIP colocalized with each other (Figure 1E). The colocalization of DOCK8, WASp, and WIP in T cells is consistent with their presence in the same complex.

WIP bridges DOCK 8 to WASp. We investigated which member of the WASp-WIP complex binds to DOCK8. DOCK8 associated with WIP in $\mathrm{T}$ cells from 2 WASP $^{\text {null }}$ patients (Figure $2 \mathrm{~A}$, immunoblot). Although there was less WIP in lysates and DOCK8 immunoprecipitates from WASP ${ }^{\text {null }} \mathrm{T}$ cells compared with what was detected in control $\mathrm{T}$ cells, the WIP/DOCK8 ratio in immunoprecipitates relative to cell lysates was not significantly different between WASp ${ }^{\text {null }} \mathrm{T}$ cells and normal $\mathrm{T}$ cells (Figure 2A, quantitative graph). The association of DOCK8 with WIP was also comparable in T cells from $\mathrm{Was}^{-/}$mice and WT controls (Figure 2B). These results indicate that DOCK8 binds to WIP independently of WASp.

WIP-deficient T cells express virtually no WASp (21) and are not suitable for determining whether DOCK8 associates with WASp independently of WIP. To determine whether DOCK8 directly binds to WIP or WASp, we examined whether recombinant DOCK8 (rDOCK8) associates with rWIP and rWASp in vitro. DOCK8-Myc, WIP-EGFP, and Flag-tagged WASp fusion proteins were generated using an in vitro wheat germ extract transcription translation system. EGFP and MALT1-Flag recombinant proteins served as negative controls. WIP-EGFP, but not EGFP, coimmunoprecipitated with DOCK8-Myc (Figure 2C, top panel), demonstrating that DOCK8 and WIP interact directly. DOCK8-Myc failed to coimmu- 
A

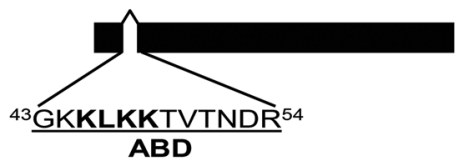

B

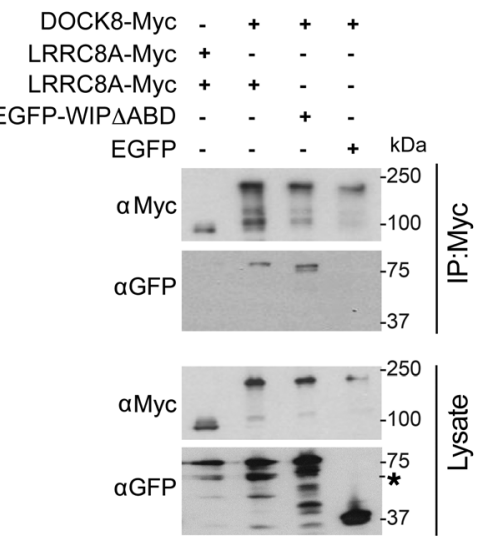

C

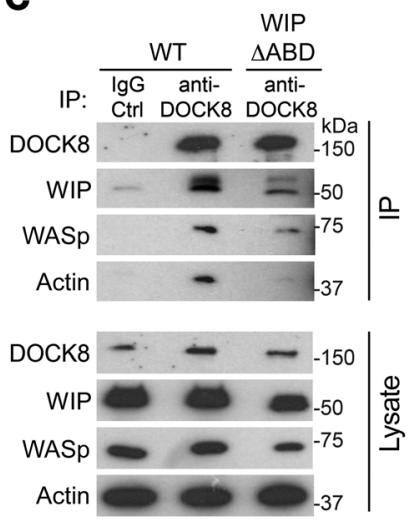

Figure 3. WIP bridges DOCK8 to actin. (A) Map of the WIP $\triangle A B D$ protein. (B) Representative immunoblot of the co-IP of WIP-EGFP and WIP $\triangle A B D$-EGFP with Myc-tagged DOCK8 in 293T cell transfectants. LRRC8A-Myc and EGFP transfectants were used as negative controls, and an aliquot of the lysates used for the coprecipitation was probed for Myc and EGFP to ensure equal loading. The * denotes a non-specific band. (C and D) Representative immunoblot (C) and quantitative analysis (D) of the co-IP of WIP, WASp, and actin with DOCK8 in splenic T cells from WT and WIP $\triangle A B D$ knockin mice. An aliquot of the lysates used for the co-IP was probed for DOCK8, WIP, WASp, and actin as a loading control. Quantification of the results was performed by calculating the relative ratio of actin/DOCK8, WIP/DOCK8, and WASp/ DOCK8 in DOCK8 immunoprecipitates relative to lysates and normalizing the values to those obtained in WT T cells by setting the WT ratio to 1 . Ctrl, control. Data are representative of $\mathbf{3}$ independent experiments in $\mathbf{B}$ and 2 independent experiments in $\mathbf{C}$ and $\mathbf{D}$. Error bars in $\mathbf{D}$ represent the mean \pm SEM
D

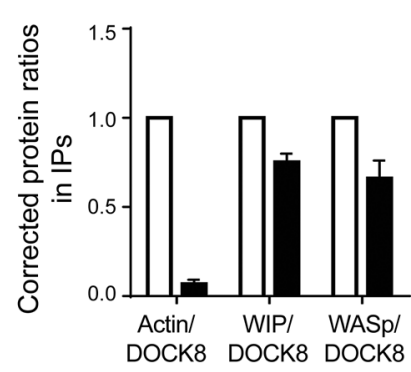

$\square$ WT

WIP $\triangle A B D$ noprecipitate with WASp-Flag in the absence of WIP-EGFP, but did so in the presence of WIP-EGFP (Figure 2C, bottom panel), but not EGFP (data not shown). WIP-EGFP coimmunoprecipitated with WASp-Flag, but not with MALT1-Flag (Figure 2C, bottom panel), as expected. These results suggest that WIP bridges DOCK8 to WASp.

We previously showed that a WIP mutant that lacks the WASp-binding domain (aa 461-488) and designated WIP $\triangle$ WBD (Figure 2D) fails to bind WASp (21). We examined the ability of WIP $\triangle$ WBD-EGFP to bind DOCK8-Myc in 293T cotransfectants by probing Myc immunoprecipitates with Ab against GFP. WIP-EGFP, but not EGFP, coprecipitated with DOCK8-Myc, but not with LRRC8A-Myc, from the lysates of the cotransfectants (Figure 2E). WIPAWBD-EGFP coprecipitated with DOCK8-Myc to an extent comparable to that seen with WIP-EGFP (Figure 2E), indicating that the WIP-binding sites for DOCK8 and WASp are distinct.

To map the WIP-binding site for DOCK8, we used 2 in-house-generated anti-WIP mAbs that recognize defined epitopes of WIP to immunoprecipitate WIP from lysates of DND41 cells. The D12C5 mAb is directed against an epitope with the core sequence ${ }^{448} \mathrm{DEWESR}^{453}$ in the C-terminus of WIP (R. Geha, unpublished observations), which was previously shown to contain the WASp-binding domain of WIP (21). IP of WIP with D12C5 disrupted the WIP and WASp interaction, however, WIPDOCK8 interaction was preserved (Figure $2 \mathrm{~F}$ ). In contrast, the $3 \mathrm{D} 10 \mathrm{mAb}$, directed against an epitope with the core sequence

${ }^{13}$ PTFALA $^{18}$ in the N-terminus of WIP (22), coprecipitated with
WASp, but not DOCK8 (Figure 2F). These results suggest that DOCK8 binds to the N-terminus of WIP, while WASp binds to the C-terminus of WIP, and are consistent with the finding of WIP bridging DOCK8 and WASp.

WIP bridges DOCK8 to actin. We previously showed that a WIP mutant that lacks the actin-binding domain (aa 43-54), designated WIP $\triangle \mathrm{ABD}$ (Figure $3 \mathrm{~A}$ ), fails to bind actin (7). We examined the ability of EGFP-WIP $\triangle$ ABD to bind DOCK8-Myc from lysates of 293T cotransfectants. EGFP-WIP $\triangle$ ABD coprecipitated with DOCK8-Myc to an extent comparable to that seen with EGFPWIP (Figure 3B), indicating that the WIP-binding sites for DOCK8 and actin are distinct.

To examine whether WIP bridges DOCK8 and actin in T cells, we examined the association of DOCK8 and actin in T cells from WT mice and mice homozygous for a knocked-in mutant Wipf1 gene that encodes for WIP $\triangle \mathrm{ABD}$ and designated WIP $\triangle \mathrm{ABD}$ mice (7). We had previously shown that actin coprecipitates with WIP in WT T cells but that this association is virtually abolished in WIP $\triangle \mathrm{ABD} T$ cells (7). Actin was readily detected in DOCK8 immunoprecipitates from WT T cells, but was virtually absent from DOCK8 immunoprecipitates from WIP $\triangle \mathrm{ABD} T \mathrm{~T}$ cells (Figure 3, C and D). There was less WIP, as well as less WASp, in lysates and DOCK8 immunoprecipitates from WIP $\triangle \mathrm{ABD} T$ cells compared with WT T cells (Figure 3C); however, the WIP/DOCK8 and WASp/DOCK8 ratios in DOCK8 immunoprecipitates relative to those in cell lysates were not significantly different in WIP $\triangle \mathrm{ABD}$ 
A
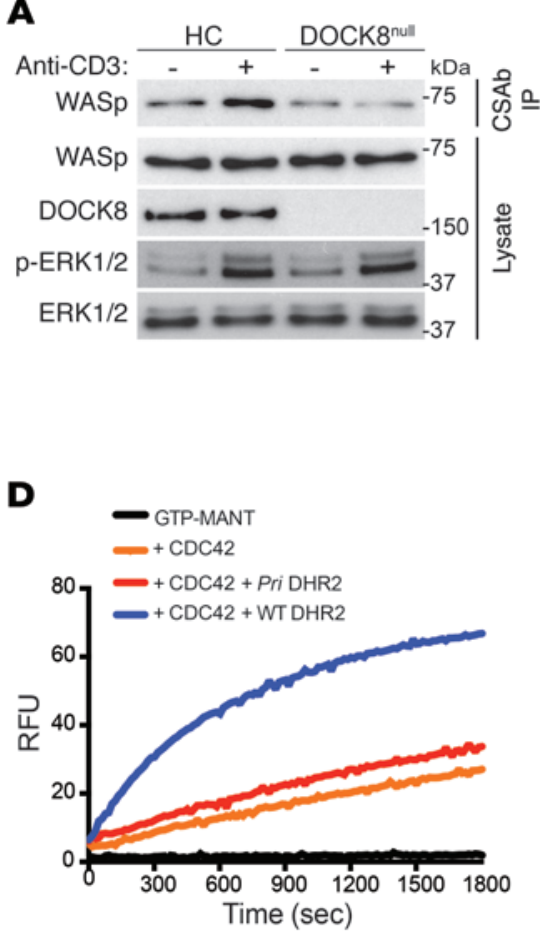

$\mathbf{F}$

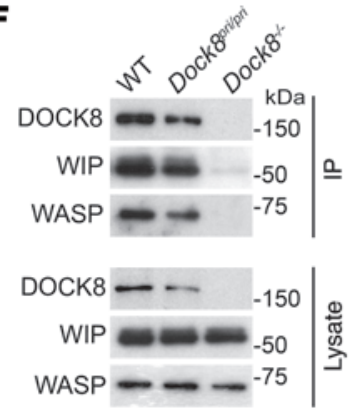

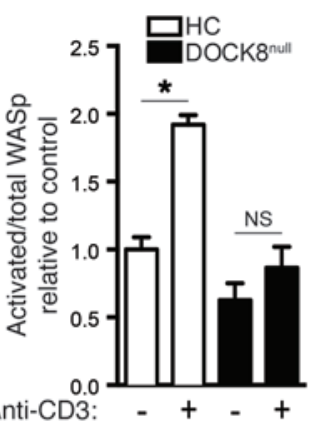

B

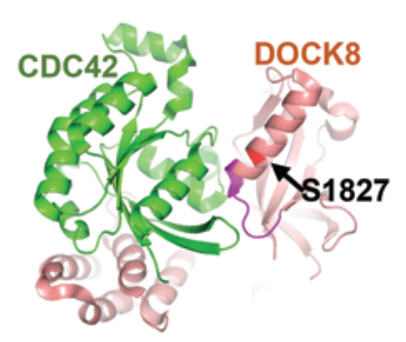

C
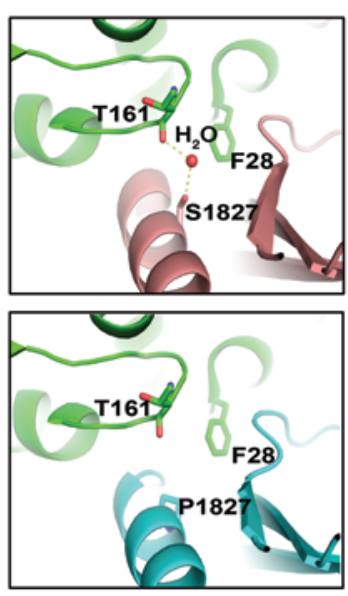
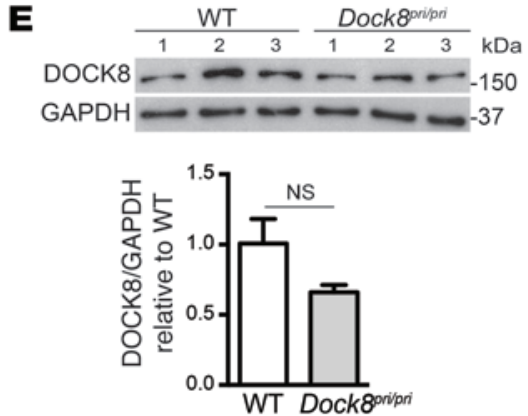

Figure 4. DOCK8 GEF activity mediates TCR-driven WASp activation. (A) Representative (left) and pooled (right) results of the generation of active WASp following TCR ligation in human T cells from an HC and a DOCK8 8 null patient as determined by immunoblotting WASp and N-WASp CSAb immunoprecipitates with anti-WASp F-8 mAb. Aliquots from total lysates were probed for WASp to ensure equal loading and for $p$-ERK $1 / 2$ to verify TCR signaling. Results are representative of 2 experiments involving 2 patients and 2 controls. Quantification was performed by calculating the ratio of activated WASp in the IP to total WASp in the lysates, relative to controls. (B) Ribbon diagram of the DOCK8-CDC42 complex. Residue $\mathrm{S} 1827$ is in red, and the region affected by the S1827P mutation is in magenta. (C) Interaction of DOCK8 residue S1827 with CDC42 (top) and its disruption by the S1827P DOCK $8^{\text {pri }}$ mutation (bottom). (D) GEF activity for CDC42 of WT DOCK8 and DOCK 8 pri DHR2 domains. Relative fluorescence units (RFU) of MANT-GTP over time are shown. Results are representative of 3 experiments. (E) Representative immunoblot and quantitation of DOCK8 expression in Dock $8^{\text {pripri }}$ and WT mice. Quantification was performed by calculating the DOCK8/GAPDH ratio relative to that in WT controls. (F and $\mathbf{G})$ Representative immunoblot (F) and quantitation (G) of the association of DOCK8 with WIP and WASp in T cells from DOCK8-mutant mice. Quantification was performed by calculating the WIP/DOCK8 ratio in DOCK8 immunoprecipitates relative to that in WT controls. (H and I) Representative $(\mathbf{H})$ and pooled (I) results of the generation of active WASp following TCR ligation in splenic T cells from Dock8 $8^{-/}$, Dock $8^{\text {pripri }}$, and WT mice. The experiment was performed and the results expressed as described in $\mathbf{A}$. Results in $\mathbf{E}-\mathbf{I}$ are representative of 3 experiments using 3 mice from each strain. Error bars in A, E, G, and I represent the mean \pm SEM. ${ }^{*} P<0.05$, by Student's $t$ test.

T cells compared with WT T cells (Figure 3D). These results indicate that WIP bridges DOCK8 to actin in T cells and suggest that WIP acts as a scaffold on which DOCK8, WASp, and actin assemble.

DOCK8 GEF activity mediates TCR-driven WASp activation. A conformation-sensitive $\mathrm{Ab}(\mathrm{CSAb})$, directed against a conserved peptide close to the GBD of N-WASp, selectively recognizes the activated, but not the nonactivated, form of WASp (23). To determine whether WASp activation following TCR ligation depends on DOCK8, WASp $\mathrm{CSAb}$ immunoprecipitates from anti-CD3-stimulated human $\mathrm{T}$ cells from 2 DOCK8 $8^{\text {null }}$ patients and 3 healthy controls (HCs) were immunoblotted with the anti-WASp F-8 mAb, which recognizes both activated and nonactivated WASp. We performed quantitative analysis of activated WASp by calculating the ratio of the intensity of the WASp band in the CSAb immunoprecipitates to that in total lysates. Activated WASp was weakly detectable in unstimulated $\mathrm{T}$ cells (Figure 4A). TCR ligation caused a significant increase in activated WASp in T cells from HCs, but not in T cells from DOCK 8 null patients (Figure 4A). TCR-driven phosphorylation of ERK was comparable in DOCK8-deficient and normal T cells. These results indicate that DOCK8 is required for TCR-driven WASp activation. 
A
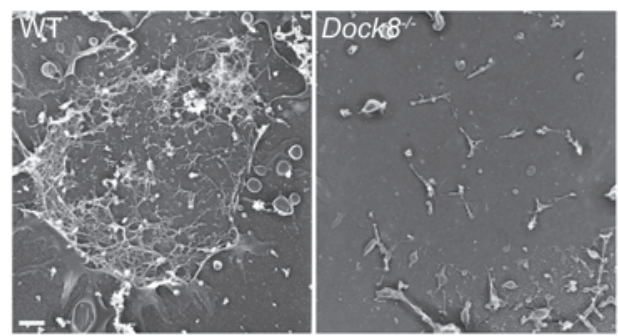

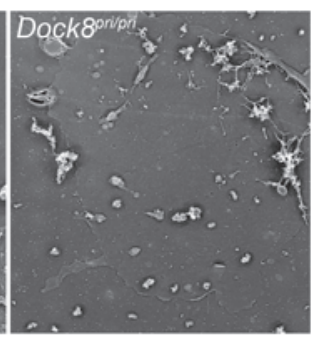

B

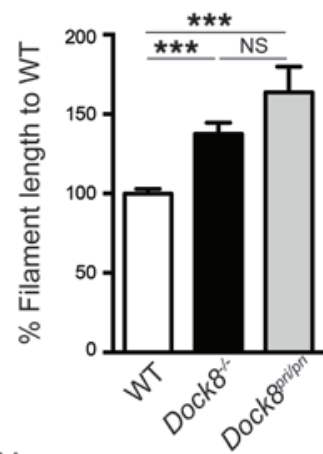

C
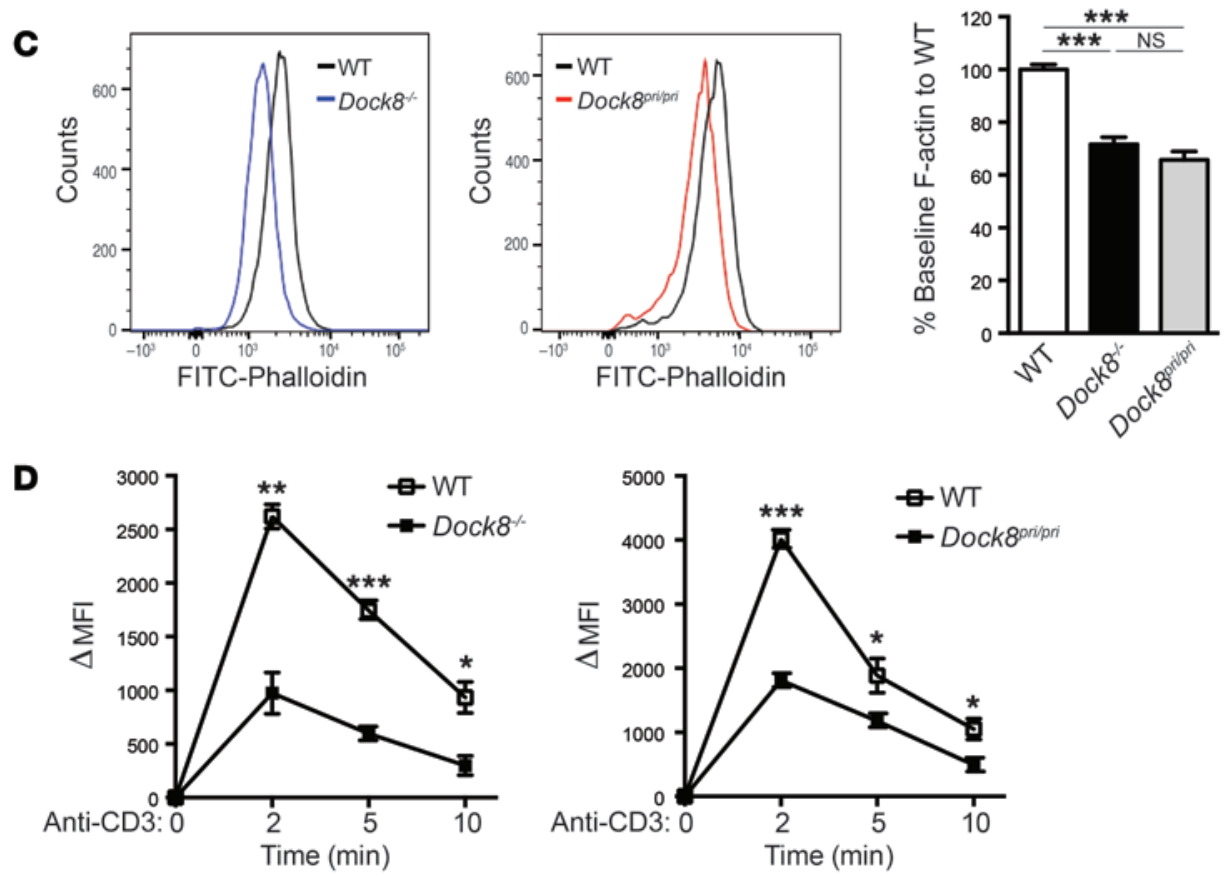

Figure 5. Defective actin cytoskeleton structure and function in DOCK8-deficient T cells. (A) Representative EM images of the apical membrane of T cells stimulated with anti-CD3 mAb. Shown are the cytoskeletal actin fibers associated with the cytoplasmic side of the adherent plasma membranes. Results are representative of 2 experiments with T cells from 1 mouse of each strain. More than 50 cells were examined in each experiment. Scale bar: 200 nm. (B) Actin filament length in T cell membranes from the Dock $8^{--}$, Dock $8^{\text {pri/pri }}$, and WT mice represented in A; 114 WT T cells, 139 Dock $8^{-/-}$T cells, and 120

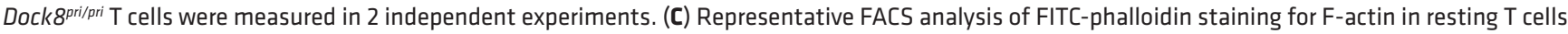
from Dock $8^{-/}$, Dock $8^{\text {pri/pri }}$, and WT mice and quantitative analysis of the results as a percentage of F-actin content in T cells from WT controls. Results are representative of 3 independent experiments using 3 mice from each strain. (D) Increase in the F-actin content of T cells from Dock $8^{-1-}$, Dock $8^{\text {pri/pri }}$, and WT mice following stimulation with anti-CD3 mAb. Results are expressed as the increase in the mean fluorescence intensity (MFI) of F-actin from the baseline (time 0). Results are representative of 3 independent experiments using 3 mice from each strain. Error bars in $\mathbf{B}$ and $\mathbf{C}$ and symbols and bars in $\mathbf{D}$ represent the mean \pm SEM. ${ }^{* * *} P<0.001,{ }^{* *} P<0.01$, and ${ }^{*} P<0.05$, by Student's $t$ test.

CDC42 has been shown to play an important role in WASp activation and actin reorganization (24-27), along with subsequent $\mathrm{T}$ cell activation, cytokine secretion, polarization, and chemotaxis (28-31). To determine the role of DOCK8 GEF activity for CDC42 in TCR-mediated WASp activation, we compared T cells from WT, Dock8 ${ }^{-/}$, and Dock $8^{p r i / p r i}$ mice. Dock $8^{-/}$mice were generated as detailed in Supplemental Figure 1A; supplemental material available online with this article; doi:10.1172/JCI85774DS1) and have no detectable DOCK8 protein expression (Supplemental Figure 1B). Dock $8^{\text {pri/pri }}$ mice carry a homozygous S1827P mutation in the DHR2 domain of DOCK8 postulated to interfere with GEF activity (11). Examination of the crystal structure of the DOCK8 DHR2-CDC42 complex (17) indicates that $\$ 1827$ is located in the middle of a long helix (residues 1823-1838) of DOCK8, whose
$\mathrm{N}$-terminal region interacts with CDC42 (Figure 4B) and engages in water-mediated interactions with CDC42 residues T161 and F28 (Figure 4C). Modeling the S1827P mutation suggests that the Pro residue probably fails to form similar interactions, which may reduce the affinity to $\mathrm{CDC} 42$ (Figure $4 \mathrm{C}$ ). Furthermore, structural dynamics simulation suggests that the S1827P mutation diminishes the interaction with CDC42 indirectly by inducing local conformational changes (data not shown). Using an in vitro exchange activity assay, we directly demonstrated that the DHR2 domain of the S1827P mutant had virtually no detectable GEF activity toward CDC42 (Figure 4D). We observed a modest, but not significant, decrease in DOCK8 expression in Dock $8^{p r i / p r i} \mathrm{~T}$ cells compared with that in WT T cells (Figure 4E). Importantly, the association of the S1827P mutant with WASp and WIP was preserved, 
A

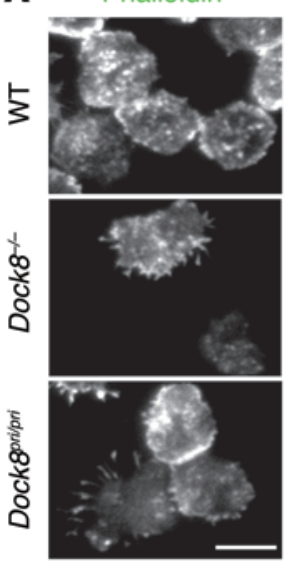

pCasL

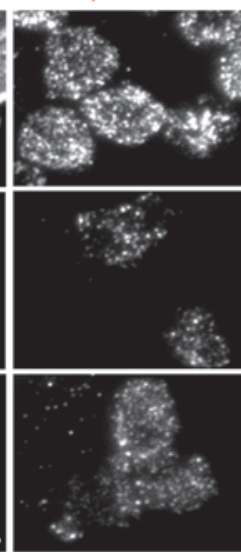

Merge

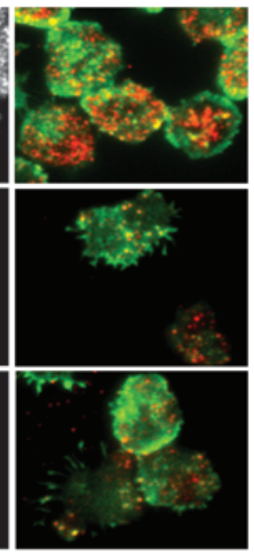

B

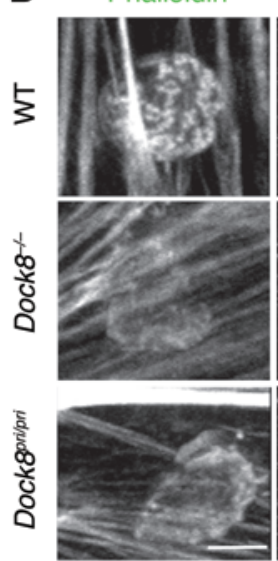

pCasL
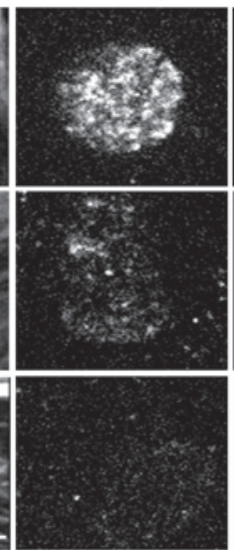

DAPI

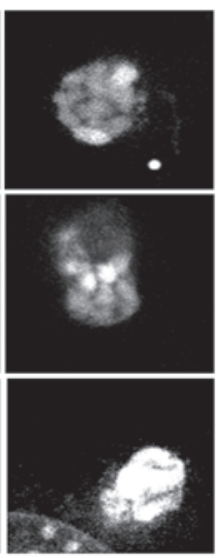

Merge

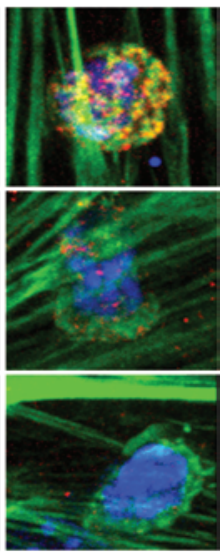

C

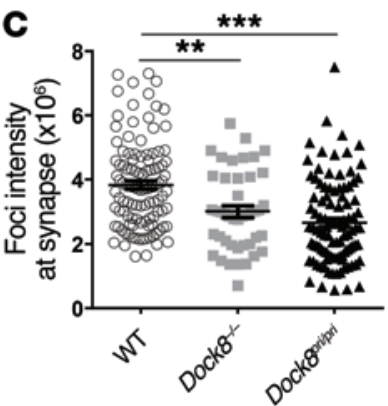

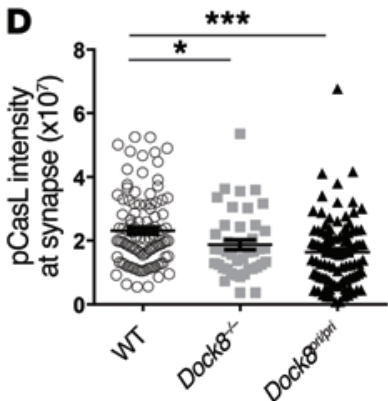
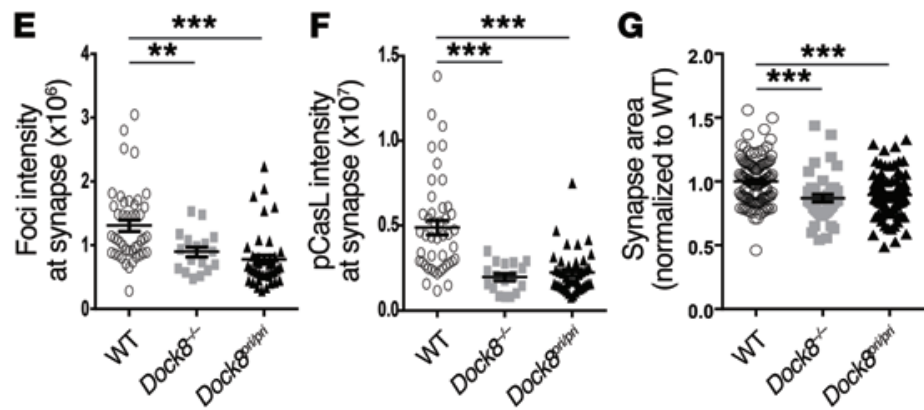

Figure 6. DOCK8 is essential for TCR-driven actin foci formation and mechanotransduction. (A and B) Representative images of splenic CD4 ${ }^{+} T$ cells from WT, Dock $8^{-1}$, and Dock $8^{\text {pripri }}$ mice plated on anti-CD3- and ICAM-1-coated glass chambers (A) or a superantigen-treated endothelial cell monolayer (B) and stained for F-actin (phalloidin, pseudocolored green) and pCasL (pseudocolored red). Orange indicates merging. The extracellular striated pattern observed in B (phalloidin panel on the left) is due to the F-actin fluorescence contributed by the endothelial cell cytoskeleton. Original magnification, $\times 100$. Scale bar: $5 \mu \mathrm{m}$. (C-G) Quantitative analysis of actin foci (C and $\mathbf{E})$, pCasL intensity ( $\mathbf{D}$ and $\mathbf{F}$ ), and synaptic area (G) in T cells. Each data point represents a value obtained for a single cell. Similar results (A-G) were obtained in 2 independent experiments. Error bars in C-G represent the mean \pm SEM. ${ }^{* * *} P<0.001$, ${ }^{*} P<0.01$, and ${ }^{*} P<0.05$, by Student's $t$ test.

as evidenced by comparable WIP/DOCK8 and WASp/DOCK8 ratios in DOCK8 immunoprecipitates from $\mathrm{T}$ cells of Dock $8^{\text {pripri }}$ and WT mice (Figure 4, F and G). TCR ligation caused a significant increase in activated WASp in T cells from WT mice, but not from Dock8 ${ }^{--}$or Dock8 ${ }^{\text {prippri }}$ mice (Figure 4, H and I). TCR-driven ERK phosphorylation was comparable in DOCK8-mutant and WT $\mathrm{T}$ cells. These results demonstrate that DOCK8 GEF activity is critical for TCR-driven WASp activation.

DOCK8 GEF activity is essential for the integrity of the subcortical actin cytoskeleton and TCR-driven actin polymerization. Given that DOCK8 is important for the activation of WASp, which regulates F-actin assembly in $\mathrm{T}$ cells (32), we examined the actin cytoskeleton and actin dynamics in DOCK8-deficient $\mathrm{T}$ cells. To evaluate the ultrastructure of the actin cytoskeleton, purified $\mathrm{T}$ cells were spread on anti-CD3-coated coverslips, their apical surface removed, and the attached cell membranes processed for electron microscopy (EM). EM images revealed that the amount of F-actin associated with the inner side of the plasma membrane was greatly diminished in Dock $8^{--}$and Dock $8^{\text {prippri }} \mathrm{T}$ cells compared with the dense, branched actin network observed in WT T cells (Figure 5A). The residual filaments in Dock8 ${ }^{--}$and Dock ${ }^{p r i p r i} \mathrm{~T}$ cells had significantly longer F-actin filaments than did WT T cells (Figure 5B). These findings indicate that DOCK8 GEF activity is important for the integrity of the T cell subcortical actin cytoskeleton.

$\mathrm{T}$ cells from Dock8 ${ }^{-/}$and Dock $8^{\text {pripri }}$ mice had significantly reduced basal F-actin levels (Figure 5C), consistent with their sparse subcortical F-actin network. Moreover, the increase in F-actin content following TCR cross-linking was significantly impaired in T cells from Dock8 - $^{-}$and Dock $8^{\text {pripri }}$ mice compared with those from WT controls (Figure 5D). These findings suggest that DOCK8 GEF activity for CDC42 is essential for maintaining the basal level of F-actin in T cells and for TCR-driven actin assembly.

DOCK8 is essential for TCR-driven actin foci formation and mechanotransduction. TCR ligation triggers foci formation at the IS, which leads to invadopodia-like $\mathrm{T}$ cell membrane protrusions that push into the target cell (6). In addition, TCR-driven actin remodeling induces mechanical strain at the IS, reflected by the phosphorylation of the mechanosensory molecule CasL (the p130Cas isoform expressed in lymphocytes) at the Y165 residue (6). Both TCR-driven actin foci formation and CasL phosphorylation are severely impaired in the absence of WASp (6). To examine the role of DOCK8 in actin foci formation and mechanical stress at the IS, T cells were plated on a glass cover- 

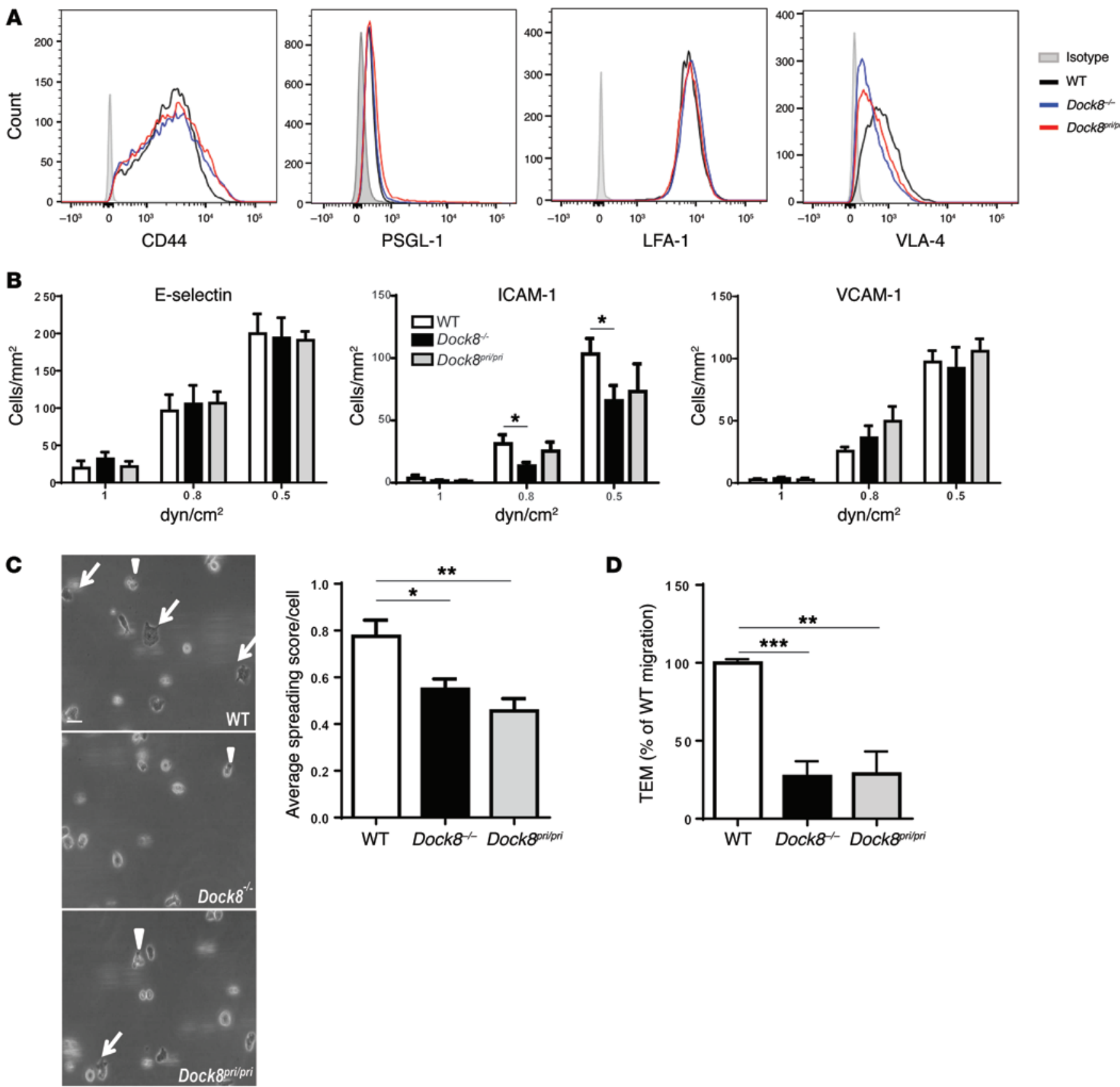

Figure 7. Defective spreading and in vitro migration of Dock8-/- and Dock8 pri/pri $^{\mathbf{T}}$ cells. (A) FACS analysis of CD44, PSCL-1, LFA-1, and VLA-4 surface expression by $\mathrm{CD}_{4}{ }^{+}$Th1 cells from Dock8 $8^{--}$, Dock $8^{\text {priprii }}$, and WT control mice. Results are representative of 3 independent experiments using 2 mice each per strain. (B) Accumulation of CD4+ Th1 cells over E-selectin-, ICAM-1 plus $250 \mathrm{ng} / \mathrm{ml}$ SDF-1 $1 \alpha-$, and VCAM-1-coated surfaces under a range of shear stress conditions. (C) Representative photomicrographs and pooled results of spreading of CD4 ${ }^{+}$Th1 cells over ICAM-1. Arrows indicate fully spread cells scored with 2 points, and solid triangles indicate partially spread cells scored with 1 point. Round, unspread cells were scored with no points to calculate the mean spreading score of cells adherent to ICAM-1 in 5 fields of view at $0.5 \mathrm{dyn} / \mathrm{cm}^{2}$. Original magnification, $\times 20$. Scale bar: $50 \mu \mathrm{m}$. Duplicate coverslips were assessed in 3 independent studies. (D) Th1 cell transmigration across a TNF- $\alpha$-treated MHEC monolayer under $0.8 \mathrm{dyn} / \mathrm{cm}^{2}$ shear stress normalized to the percentage of WT Th1 cells. Pooled results in B-D represent 3 independent experiments each using CD4+ Th1 cells from 1 mouse per strain. ${ }^{* * *} P<0.001$, ${ }^{* *} P<0.01$, and ${ }^{*} P<0.05$, by Student's $t$ test.

slip coated with anti-CD3 mAb and ICAM-1, and actin foci formation and phosphorylated CasL (p-CasL) levels were assessed using total internal reflection microscopy. F-actin foci formation and p-CasL were significantly reduced in Dock $8^{-/}$and Dock $8^{\text {pri/pri }}$ $\mathrm{T}$ cells compared with that detected in WT T cells (Figure 6, A, $\mathrm{C}$, and D). To better mimic the physiologic interactions between
$\mathrm{T}$ cells and vascular endothelium, $\mathrm{T}$ cells were plated on a superantigen-loaded endothelial cell monolayer, and cell-cell contacts were examined by spinning-disc confocal microscopy. WT T cells plated on the endothelial monolayer exhibited robust F-actin foci formation and CasL phosphorylation; both were significantly reduced in Dock8 $8^{-/}$and Dock pri/pri $^{\text {T }}$ cells (Figure 6, B, E and F). 
A
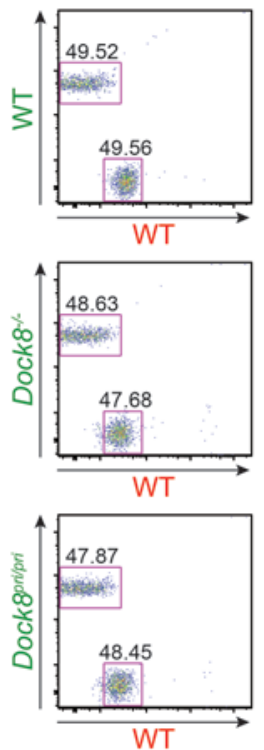

C

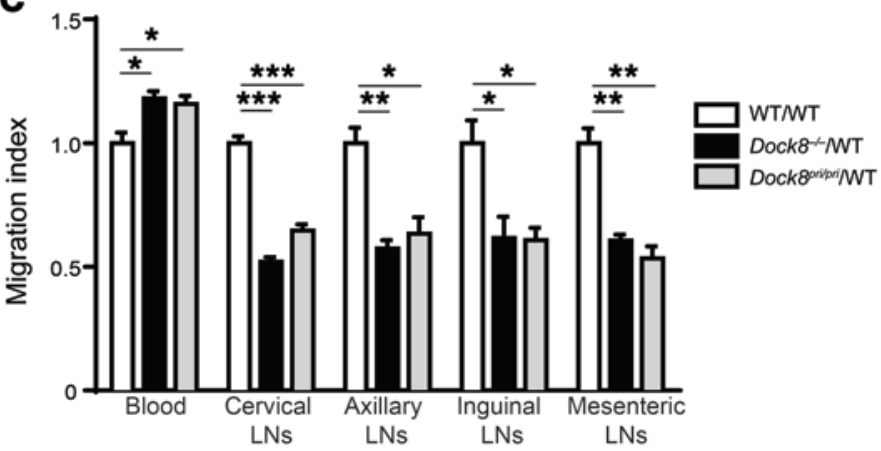

B
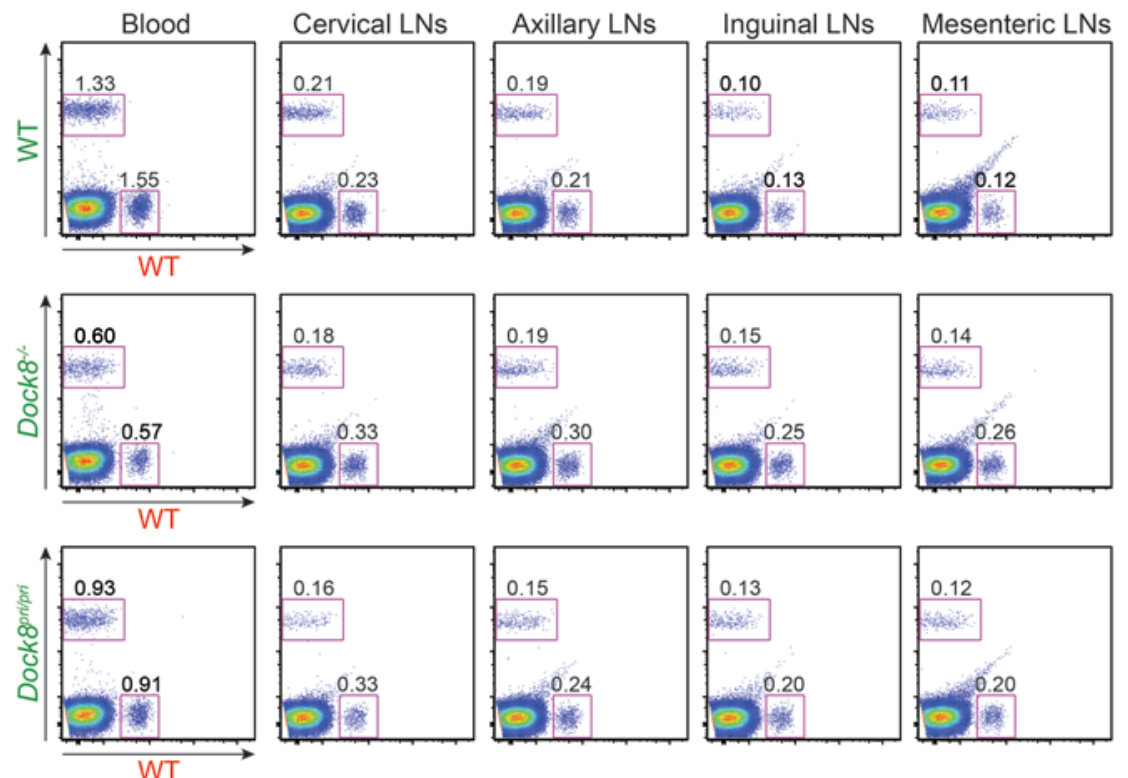

Figure 8. Defective in vivo homing of DoCK8-deficient T cells. (A) Representative FACS analysis of a mixture of equal numbers of Alexa Fluor 555-labeled WT T cells (designated by red lettering) and Alexa Fluor 488-labeled WT, Dock8 $8^{-/}$, and Dock8 $8^{\text {pri/pri }}$ T cells (designated by green lettering) used for injection into genetically matched WT recipients. (B) Representative FACS plots from the blood and LNs of WT recipients 1 hour after i.v. administration of 1:1 mixtures of Alexa Fluor 555-labeled WT T cells and Alexa Fluor 488-labeled WT, Dock8 ${ }^{-/-}$, or Dock8 pri/pri T cells. (C) Quantitative analysis of cells from the blood and LNs of WT recipients obtained 1 hour after i.v. administration of 1:1 mixtures of equal numbers of Alexa Fluor 555-labeled WT T cells and Alexa Fluor 488-labeled WT, Dock8 $8^{-/}$, or Dock $8^{\text {pri/pri }}$ T cells. Graph shows the homing index of T cells from Dock $8^{-/-}$, Dock $8^{\text {pri/pri }}$, and WT mice relative to the mean homing index of WT T cells set at 1.0. (D) Percentages of annexin V+ eFluor-780- apoptotic cells and eFluor-780+ dead cells among Alexa Fluor 488-labeled WT, Dock $8^{-/-}$, and Dock $8^{\text {pripri }}$ donor T cells in pooled LN cells from WT recipients. Results in A-D are representative of 2 independent experiments each using 5 recipients per donor strain. Error bars represent the mean \pm SEM. ${ }^{* *} P<0.001,{ }^{* *} P<0.01$, and ${ }^{*} P<0.05$, by Student's $t$ test.

In addition, the area of the IS was significantly reduced in T cells from $\mathrm{Dock}^{-/-}$and Dock8 $8^{\mathrm{pr} / \mathrm{pri}}$ mice compared with that of $\mathrm{T}$ cells from WT controls (Figure 6G). These results show that DOCK8 GEF activity for CDC42 is important for TCR-driven formation of actin foci and generation of mechanical force at the IS.

DOCK8 is essential for $T$ cell spreading and in vitro TEM. Dynamic rearrangements of the actin cytoskeleton, including actin foci formation, are important for $\mathrm{T}$ cell motility and transcellular diapedesis (33). Splenic CD4 ${ }^{+} \mathrm{T}$ cells from Dock8 ${ }^{-/}$and Dock8 pripri mice migrated normally toward SDF1 $\alpha$ under static conditions in a 2D Transwell migration assay (data not shown), like $\mathrm{T}$ cells from Dock8 $8^{c p m} / c^{p m}$-mutant mice (34). Migration of T cells from blood vessels into tissues occurs under physiological shear flow conditions and involves sequential interactions between adhesion molecules expressed on $\mathrm{T}$ cells and endothelial cells, including selectin-mediated rolling and tethering, followed by chemokine-induced integrin-mediated firm adhesion and arrest, spreading, and TEM (35). In vitro Th1-polarized $\mathrm{CD}^{+} \mathrm{T}$ cells show high TEM activity and are routinely used to study this process in vitro (36). We generated Th1 T cells in vitro from Dock8 ${ }^{--}$, Dock8 $8^{\text {pripri }}$, and WT mice by stimulating splenic $\mathrm{CD} 4{ }^{+} \mathrm{T}$ cells with anti-CD3 and anti-CD28 under Th1-polarizing conditions. The percentage of generated Th1 cells determined by intracellular staining for IFN- $\gamma$ was comparable between the 3 groups $\left(76.8 \% \pm 13.3 \%\right.$ for Dock $8^{-/}, 77.8 \% \pm 13.5 \%$ for Dock $8^{\text {pripri }}$, and $84.3 \% \pm 3.6 \%$ for WT T cells). Th1 cells from all 3 groups had comparable surface expression of the selectin ligands CD44 and P-selectin glycoprotein ligand 1 (PSGL-1) and the integrins LFA-1 and VLA-4, which mediate adhesion to ICAM-1 and VCAM-1, respectively (Figure 7A). The accumulation of Th1 cells on immobilized E-selectin-Fc and VCAM-1-Fc chimeric proteins under a range of physiological flow conditions $\left(0.5-1.0\right.$ dynes $\left./ \mathrm{cm}^{2}\right)$ was comparable among Dock8 ${ }^{-/}$, Dock8 $8^{\text {prippri }}$, and WT mice (Figure 7B). 
Resting

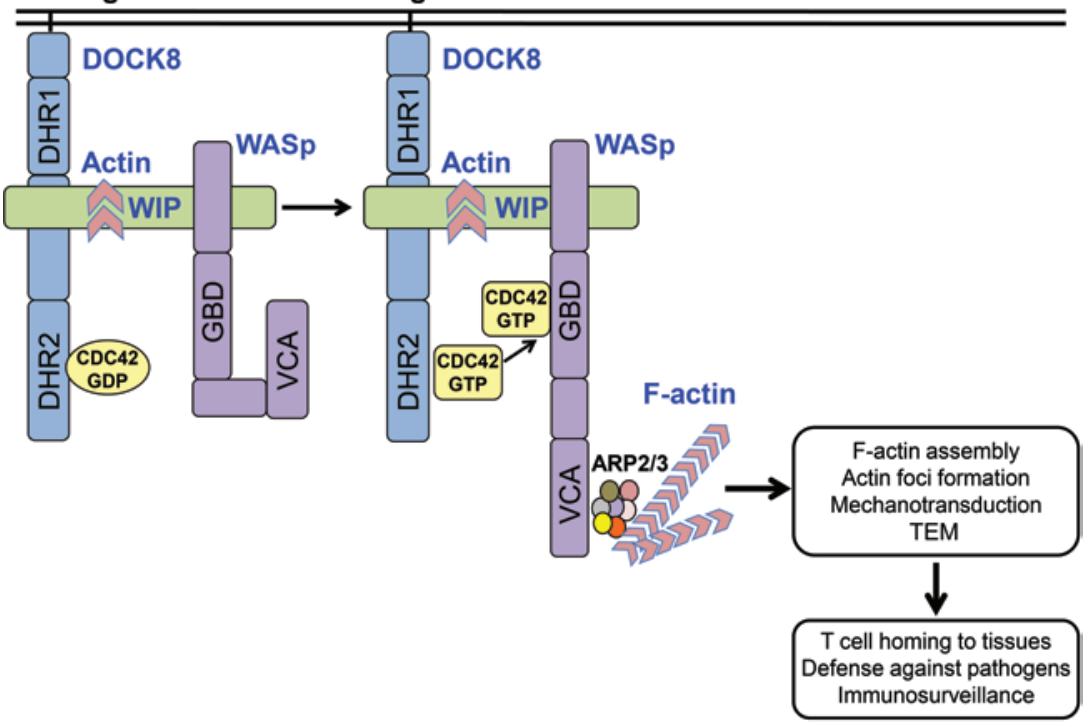

Figure 9. A DOCK8-WIP-WASp complex links the TCR to the actin cytoskeleton reorganization. DOCK8, WIP, and WASp exist in a complex in T cells. TCR ligation activates DOCK8, promoting its CEF activity for CDC42. CDC42-GTP generated by DOCK8 binds to WASp, which is closely associated with DOCK8, causing it to assume an open conformation that allows its C-terminal verproliin, central, acidic (VCA) domain to bind to the ARP2/3 complex and initiate actin polymerization. The generated F-actin is stabilized by binding to WIP and is essential for actin cytoskeleton-dependent $T$ cell functions. These include actin foci formation at the immune synapse, mechanotransduction, and TEM into LNs and tissues, both of which are critical for T cell-mediated immune surveillance.
However, a significant decrease of $57 \%$ and $36 \%$ in the adhesion of Dock8 $8^{--}$Th1 cells to ICAM-1-Fc (coimmobilized with SDF1 $\alpha$ ) was observed at 0.8 and 0.5 dynes $/ \mathrm{cm}^{2}$, respectively. There was an $18 \%$ and $29 \%$ decrease in the adhesion of Dock $8^{p r i p r i}$ Th1 cells to ICAM-1$\mathrm{Fc}$ at 0.8 and 0.5 dynes $/ \mathrm{cm}^{2}$, respectively, but these decreases were not statistically significant. These findings suggest that DOCK8 functions, beyond its GEF activity, may contribute to optimal LFA1-dependent Th1 cell adherence to ICAM-1 under shear flow conditions. Next, DIC microscopic recordings of adherent Th1 cells were analyzed to assess their ability to undergo spreading after arrest on ICAM- 1 and SDF- $1 \alpha$, which revealed a significant reduction in the spreading of Th1 cells from Dock8 ${ }^{-/-}$and Dock $8^{p r i p r i}$ mice compared with that seen in Th1 cells from WT mice (Figure 7C).

We directly examined the capacity of Th1 cells to arrest, crawl over, and transmigrate across a TNF- $\alpha$-activated murine endothelial cell monolayer under physiological low-flow conditions (0.8 dynes $\left./ \mathrm{cm}^{2}\right)$. Th1 cells from Dock8 $8^{-/-}$and Dock $8^{p r i / p r i}$ mice adhered normally to the monolayer; however, the fraction of adherent cells that transmigrated was significantly lower for Dock8 $8^{-/}$and Dock8 ${ }^{\text {pripri }} \mathrm{T}$ cells than for WT T cells (Figure 7D). These results suggest that DOCK8 GEF activity is important for T cell spreading and TEM under shear flow conditions.

DOCK8 is essential for $T$ cell homing to lymph nodes. Circulating $\mathrm{T}$ cells enter lymph nodes (LNs) by migrating across high endothelial venules (37). To examine the role of DOCK8 in the in vivo $\mathrm{T}$ cell homing to LNs, equivalent numbers of Alexa Fluor 488-labeled Dock8 ${ }^{-/}$, Dock8 $8^{\text {prippri }}$, or WT T cells were mixed with Alexa Fluor 555-labeled WT T cells and administered i.v. to WT recipients. One hour later, the percentages of transferred WT and Dock8 ${ }^{-/}$or Dock8 $8^{\text {pripri }} \mathrm{T}$ cells were analyzed in the blood and cervical, axillary, mesenteric, and inguinal LNs by flow cytometry (Figure 8, A and B). The homing index was calculated as the ratio of Alexa Fluor 488- to Alexa Fluor 555-labeled cells and normalized to the ratio of WT controls. The homing index of $D o c k 8^{-/-}$and Dock8 ${ }^{\text {pripri }} \mathrm{T}$ cells was significantly decreased in all LNs examined (Figure 8C). There was a significantly higher retention of Dock8 $8^{-/-}$ and Dock8 $8^{\text {pripri }} \mathrm{T}$ cells in the blood (Figure $8 \mathrm{C}$ ). Similar results were obtained when the cell-labeling dyes were reversed (data not shown). Migration of DOCK8-deficient T cells through 3D spaces that constrain cell movement results in catastrophic cell death that becomes evident after 12 hours (13). Analysis of LNs from WT recipients 1 hour after adoptive transfer revealed no significant differences in the percentages of apoptotic cells or dead cells among Dock8 $8^{-/}$, Dock8 $8^{\text {pripri }}$, and WT donor T cells (Figure 8D). These results suggest that DOCK8 GEF activity is important for the homing of naive T cells to LNs.

\section{Discussion}

We demonstrate that DOCK8 and WASp constitutively associate in T cells in a complex in which WIP bridges DOCK8 to WASp and actin and that DOCK8 GEF activity is essential for TCR-driven WASp activation and actin cytoskeleton reorganization. We also show that DOCK8 GEF activity is important for the integrity of the subcortical actin cytoskeleton in $\mathrm{T}$ cells and for a number of actin cytoskeleton-mediated $\mathrm{T}$ cell functions that also depend on WASp. These findings establish a mechanistic basis for the phenotypic convergence of DOCK8 deficiency and WASp deficiency.

IP studies demonstrated that DOCK8 constitutively associates with WASp and its partner WIP in human and murine T cells. Consistent with this finding, DOCK8 colocalized with WASp and WIP in the T cell line DND41. The association of DOCK8 with WASp and WIP was not altered by TCR ligation, indicating that TCR-driven posttranslational modifications of these proteins have no detectable effect on the DOCK8-WIP-WASp complex. The association of DOCK8 with WIP was direct and independent of WASp. In contrast, WIP was essential for the association of DOCK8 and WASp. WIP was also found to mediate the association between DOCK8 and actin, and the WIP-binding sites for DOCK8, WASp, and actin were found to be distinct. This suggests that WIP serves as a scaffold on which DOCK8, WASp, and actin assemble.

Using cells from DOCK $8^{\text {null }}$ patients and mice and an $\mathrm{Ab}$ that selectively recognizes the open, active conformation of WASp, we established that DOCK8 is critical for TCR-driven WASp activation in T cells. More importantly, we demonstrated that DOCK8 GEF 
activity was essential for WASp activation, because TCR ligation failed to activate WASp in T cells from $D o c k 8^{-/-}$and $D o c k 8^{\text {pri/pri }}$ mice, which express a mutant DOCK8 protein with a missense mutation in the DHR2 domain that we show abolishes CDC42-directed GEF activity. These findings place DOCK8 upstream of WASp and suggest that the spatial proximity of DOCK 8 and WASp may facilitate WASp activation following TCR ligation. The mechanism by which TCR ligation triggers DOCK8 GEF activity is not known. CCR7 signaling in T cells induces MST1 and MST2 kinase-dependent phosphorylation of MOB1, causing it to associate with DOCK8 and promote its GEF activity (38). TCR ligation activates MST1 (39), thus, MST1 and MOB1 may link the TCR to DOCK8 in T cells.

DOCK8, and in particular DOCK8 GEF activity, were found to be essential for the integrity and function of the actin cytoskeleton in T cells. The subcortical actin network was severely attenuated in T cells from Dock8 ${ }^{-/-}$and Dock8 $8^{\text {prippri }}$ mice. Disruption of the subcortical actin network is also observed in WASp-deficient T cells, albeit to a lesser extent than in DOCK8-deficient and WIPdeficient T cells $(40,41)$, suggesting that DOCK8 and WIP may regulate actin dynamics independently of WASp. In this regard, WIP binds to cortactin, which can drive F-actin assembly (42), and DOCK8 may have GEF activity for RAC1, which activates WASp family verprolin-homologous protein (WAVE) to drive actin polymerization (38). WASp facilitates the branching of filamentous actin in T cells by activating the ARP2/3 complex (43). The residual F-actin filaments in Dock8 ${ }^{-/-}$and Dock8 $8^{\text {pripri }}$ T cells were significantly elongated, possibly because of impaired branching due to deficient WASp-mediated ARP2/3 activation in these cells.

Baseline F-actin levels were significantly decreased, and TCR-driven F-actin assembly as well as IS formation were impaired in DOCK8-mutant T cells, as in WASp-deficient and WIP-deficient T cells $(2,40,44,45)$; this further suggests that DOCK8, WIP, and WASp form a functional unit. Defective accumulation of F-actin at the IS has been demonstrated in T cells from Dock8 ${ }^{\text {pripri }}$ mice (10). The residual increase in TCR-driven F-actin assembly in DOCK8-deficient $\mathrm{T}$ cells may be explained by CDC42-independent activation of WASp $(2,46)$, as well as by WASp-independent pathways of actin polymerization, e.g., via WAVE (47). Residual activation of WASp via CDC42-independent pathways may also explain the less severe effect of DOCK8 deficiency on F-actin foci formation compared with that of WASp deficiency (6).

$\mathrm{T}$ cell extravasation across the endothelial cell lining is essential for the recruitment of effector T cells to sites of infection, immunosurveillance, and tolerance (48). Dock8 ${ }^{-/-}$and Dock$8^{\text {pripri }}$ Th1 effector cells expressed selectin ligands normally and adhered normally to immobilized VCAM-1 and E-selectin. It has been established that circulating $\mathrm{T}$ cells constitutively express VLA-4 integrins in conformations that recognize VCAM-1 under flow conditions (49). The comparable adhesion of Dock8 $8^{-1}$, Dock $8^{\text {prippri }}$, and WT Th1 cells to VCAM-1 suggests that expression of these active conformations by $\mathrm{T}$ cells is independent of DOCK 8 activity. In contrast, Dock8 ${ }^{-/-}$Th1 cells adhered significantly less to ICAM-1 compared with WT Th1 cells under shear flow conditions. Although Dock8 ${ }^{\text {pripri }}$ Th1 cell adhesion was lower than that of WT Th1 cells, the decrease did not reach statistical significance. These results suggest that DOCK8 functions, beyond its GEF activity, contribute to optimal LFA-1-dependent
Th1 cell adherence to ICAM-1 under shear flow conditions. In this respect, DOCK8 is known to interact with talin and protein tyrosine kinase 2 (PYK2), both of which play a role in integrin-mediated cell adhesion $(19,50-52)$. Post-arrest spreading of both Dock8 $^{-/-}$and Dock8 $8^{\text {pripri }}$ effector cells on ICAM-1 coimmobilized with SDF- $1 \alpha$ was reduced compared with WT cells. A similar spreading defect has been observed in WASp- and WIP-deficient T cells $(40,53)$. Importantly, Th1 cells that lacked DOCK8 or expressed a DOCK8-mutant deficient in GEF activity showed a striking reduction in their ability to transmigrate across a TNF- $\alpha$-activated murine endothelial cell monolayer, a scenario that mimics the egress of effector $\mathrm{T}$ cells from blood vessels into an inflamed tissue. Moreover, both DOCK8-deficient and DOCK8-mutant T cells were defective in their ability to home to LNs. Defects in TEM have been documented in WASp- and WIP-deficient T cells $(54,55)$ as well as in LFA-1and ICAM-1-deficient T cells (56). The reported normal homing of mature thymocytes from Dock $8^{\mathrm{cpm} / \mathrm{cpm}}$ mice to LNs (34) may reflect differences between mouse strains and between thymocytes and splenic T cells. Decreased contact with the substrate due to defective spreading, defective formation of actin foci, podosome equivalents important for pushing through endothelial cells, and reduced mechanotransduction may all contribute to the impaired TEM and defective homing to LNs of DOCK8deficient $\mathrm{T}$ cells.

In summary, our data demonstrate that a DOCK8-WIPWASp complex links the TCR to the actin cytoskeleton. The spatial proximity of DOCK8, WASp, and actin in this complex ensures that CDC42 activated by DOCK8 following TCR ligation drives WASp-mediated actin polymerization, as illustrated in Figure 9. Moreover, we show that DOCK8-deficient $\mathrm{T}$ cells share with WASp-deficient T cells a number of actin cytoskeletal defects that include an attenuated subcortical actin cytoskeleton, reduced F-actin content, defective TCR-driven actin assembly, actin foci formation and mechanotransduction, and impaired TEM and homing to LNs. These defects probably contribute to the susceptibility of DOCK8-deficient and WASp-deficient patients to infections, allergy, autoimmunity, and malignancy. Collectively, our findings provide a mechanistic explanation for the shared features of DOCK8 and WASp deficiencies.

\section{Methods}

Mice. Was $^{-/}$mice, a gift of Scott Snapper (Boston Children's Hospital, Boston, Massachusetts, USA) have been previously described (57). Homozygous knockin WIP $\triangle \mathrm{ABD}$ mice that express a WIP mutant lacking the actin-binding domain (ABD) (aa 43-54) are described in ref. (7). The generation of Dock8 $8^{-/}$mice, which carry a homozygous knockin c.C1074T mutation that introduces a stop codon in exon 9 of the endogenous Dock8 gene is described in Supplemental Figure 1. This mutation recapitulates a mutation in a DOCK 8 null patient (16). Mice were generated using standard techniques and mated with mice expressing the Flp recombinase under the control of the Rosa promoter to remove the neo gene. The homozygous mutant mice, which express no detectable DOCK8 protein and are designated Dock8 ${ }^{-/-}$mice, were then bred for 10 generations on the C57BL/6 background. Dock8 pripri mice, generated by $N$-ethyl- $N$-nitrosourea mutagenesis from a pure 
C57BL/6 background, carry a homozygous S1827P mutation in the DOCK8 DHR2 domain as previously described (11). WT C57BL/6 mice (Charles River Laboratories) were bred in our facility. Mice were sacrificed at 7 to 12 weeks of age for harvesting of LNs and spleen and at 8 to 12 days of age for harvesting of heart endothelial cells. All mice were housed under specific pathogen-free conditions.

Patients. Blood samples were obtained from healthy volunteers, 3 DOCK8-deficient patients with homozygous mutations in DOCK8 (c. T181A p.Ser1357X, deletion of exons 1-3, and deletion of exons 10-12) that abolish DOCK8 expression, and 2 WAS patients with mutations in WAS (c.G291A p.R86H, and c.559+5G>A donor splice-site mutation in intron 6) that abolish WASp expression.

Cell isolation. Human peripheral blood mononuclear cells (PBMCs) were isolated from whole blood by Ficoll-Paque PLUS density gradient centrifugation (GE Healthcare). T cells were purified from PBMCs by negative selection using a Pan T Cell Isolation Kit II (Miltenyi Biotec). Mouse LNs and spleens were harvested and processed into single-cell suspensions. Splenocytes were rid of red cells by treating them with ACK lysing buffer (Life Technologies, Thermo Fisher Scientific). Splenic $\mathrm{CD}^{+}$and $\mathrm{CD} 4^{+} \mathrm{T}$ cells were purified by negative selection using a mouse Pan T Cell Isolation Kit II and CD $4^{+} \mathrm{T}$ Cell Isolation Kit, respectively (Miltenyi Biotec).

Cell cultures. The T cell acute lymphocytic leukemia (T-ALL) cell line DND41 (58) was obtained from the ATCC and maintained in RPMI 1640 supplemented with $10 \% \mathrm{FBS}, 100 \mathrm{U} / \mathrm{ml}$ penicillin G, and $100 \mu \mathrm{g} / \mathrm{ml}$ streptomycin. Murine CD4 ${ }^{+}$Th1 cells were derived from naive T cells by anti-CD3 $\varepsilon$ (mAb 145-2C11) and anti-CD28 (mAb E18) stimulation (both from BioLegend) in the presence of anti-IL-14 mAb (clone 11B11; BioLegend) and recombinant IL-12 and IL-2 (R\&D Systems) as previously described $(36,59)$. Murine heart endothelial cells (MHECs) were prepared from 8- to 12-day-old WT C57BL/6 mice as previously described $(36,59)$.

Cell stimulation. Human $\mathrm{T}$ cells were incubated with $10 \mu \mathrm{g} / \mathrm{ml}$ mouse anti-human CD3 mAb OKT3 (eBioscience) for 10 minutes at $37^{\circ} \mathrm{C}$, followed by cross-linking with $20 \mu \mathrm{g} / \mathrm{ml} \mathrm{F}\left(\mathrm{ab}^{\prime}\right)_{2}$ goat anti-mouse IgG secondary $\mathrm{Ab}$ (Jackson ImmunoResearch Laboratories) for the times indicated in the figures and figure legends at $37^{\circ} \mathrm{C}$. For mouse $\mathrm{T}$ cells, rat anti-mouse CD3 mAb KT3 (Serotec) and goat F(ab') ${ }_{2}$ anti-rat IgG secondary Ab (Jackson ImmunoResearch Laboratories) were used.

Cell transfection. HEK293 cells were cotransfected using the lipofectamine LTX and PLUS reagents from Invitrogen with plasmids encoding the fusion proteins DOCK8-Myc, LRRC8A-Myc, WIP-EGFP, and WIP $\triangle \mathrm{ABD}$-EGFP, which lacks the actin-binding domain of WIP (aa 43-54) (7), or WIP $\triangle$ WBD-EGFP, which lacks the WASp-binding domain of WIP (aa 461-488) (21).

Generation of recombinant proteins by in vitro transcription and translation. In vitro transcription and translation reactions were performed using the TNT T7-coupled wheat germ extract system (Promega), according to the manufacturer's instructions. The following constructs (vectors) were used: DOCK8-Myc/His (pcDNA6/Myc-His; Invitrogen, Thermo Fisher Scientific); WIP fused to EGFP (WIP-EGFP) and EGFP alone (pcDNA6/V5-His; Invitrogen, Thermo Fisher Scientific); and WASp-Flag and MALT1-Flag (pcDNA3.1/Flag; Addgene plasmid 20011, a gift of Stephen Smale (David Geffen School of Medicine, UCLA, Los Angeles, California, USA) (60)). The pcDNA6/Myc-His (DOCK8), pcDNA6/V5-His (WIP-EGFP or EGFP), pcDNA3.1/Flag (WASp), and pcDNA3.1/Flag (MALT1) vectors were linearized by PmeI, XbaI, BclI, and DraIII restriction enzymes, respectively. The coupled transcription-translation reactions were performed at $30^{\circ} \mathrm{C}$ for 90 minutes. Purified linearized DNA $(0.5 \mu \mathrm{g})$ served as the template in a final volume of $50 \mu \mathrm{l} /$ reaction. The resulting products were used for IP.

Abs. The following Abs were used: rabbit anti-DOCK8 polyclonal Ab (HPA003218-100UL; Sigma-Aldrich); mouse anti-DOCK8 mAb G-2 (SC-376911/G-2; Santa Cruz Biotechnology); mouse anti-WASp mAb F-8 directed against aa 197-222 (SC-365859/F-8; Santa Cruz Biotechnology); rabbit anti-MALT1 (2494S; Cell Signaling Technology), rabbit anti-GAPDH (2118S/ 14C10; Cell Signaling Technology), and rabbit anti-p-ERK1/2 polyclonal Abs (9102S; Cell Signaling Technology); rabbit IgG isotype (sc-3888; Santa Cruz Biotechnology); rabbit WASp/NWASp CSAb (61); in-house-generated mouse anti-WIP 3D10 mAb (22) and D12C5 mAb; mouse anti-Myc mAb 9E10 (05-419/9E10; EMD Millipore); mouse anti-GFP (66002-1-Ig; Proteintech); rabbit anti-GFP D5.1 mAb (2956/D5.1; Cell Signaling Technology); and mouse anti-Flag M2 mAb (F3165/M2; Sigma Aldrich). The DOCK8, WASp, WIP, and MALT1 Abs recognize both human and mouse proteins.

IP and immunoblotting assays. Cells were lysed in 0.5\% NP-40 buffer (150 mM NaCl, 25 mM Tris-Cl, pH 7.5, 5 mM EDTA) containing complete protease inhibitors (Roche). Cell lysates or mixtures of epitope-tagged recombinant proteins were incubated with the Abs indicated in the figure legends. Immune complexes were captured with protein G-sepharose (EMD Millipore), washed, denatured by boiling in sample buffer, separated on acrylamide gels, and analyzed by immunoblotting with the Abs indicated in the figures. Protein band intensities were quantified by densitometry using ImageJ software (NIH).

Flow cytometry. Standard flow cytometric methods were used to evaluate cell-surface marker expression using the following Abs (clones): PE-Cy7 anti-mouse CD44/L-selectin ligand IM7 mAb and PE-Cy7 anti-mouse CD49d/VLA-4 $\alpha$ R1-2 mAb from BioLegend; PE anti-mouse CD11a/LFA-1 $\alpha$ M17/4 mAb from eBioscience; and PSGL-1/ P-selectin ligand $2 \mathrm{PH} 1 \mathrm{mAb}$ from BD Biosciences. T cells activated under Th1-polarizing conditions were processed for intracellular staining using a BD Cytofix/Cytoperm Fixation/Permeabilization Solution Kit (BD Biosciences) and stained with eFluor 450 anti-mouse IFN- $\gamma$ mAb XMG1.2 (eBioscience) to corroborate the differentiation of Th1 cells. Samples were acquired on a BD LSRFortessa cell analyzer using FACSDiva software (BD Biosciences). Analyses were performed using FlowJo software (Tree Star).

Immunofluorescence and confocal microscopy. DND41 cells $\left(5 \times 10^{5}\right.$ cells) were plated on fibronectin-coated coverslips ( $20 \mu \mathrm{g} / \mathrm{ml}$ in PBS) overnight and then fixed with $4 \%$ paraformaldehyde for 10 minutes at room temperature. Fixed cells were permeabilized with $0.2 \%$ saponin-0.2\% BSA in PBS for 20 minutes at room temperature and incubated overnight at $4^{\circ} \mathrm{C}$ with the following primary Abs: rabbit polyclonal anti-DOCK8 H-159 (Santa Cruz Biotechnology Inc.) paired with mouse anti-WASp mAb F-9 (Santa Cruz Biotechnology Inc.) or mouse anti-WIP 3D10 mAb. In addition, we used mouse anti-WIP 3D10 mAb paired with rabbit polyclonal anti-WASp (Bethyl Laboratories). Goat anti-mouse Alexa Fluor 488 and donkey anti-rabbit Alexa Fluor 594 secondary Abs (Life Technologies, Thermo Fisher Scientific) were added for 1 hour at room temperature. Differential interference contrast (DIC) images and immunofluorescence images were acquired on an LSM700 confocal laser scanning microscope with Plan-Apochromat $63 \times / 1.40$ Oil DicM27 objective using the acquisition software Zen 2009 (Zeiss). Analyses were performed using ImageJ software. 
Structural modeling of the S1827P mutation. The structural flexibility of WT DOCK8 and the S1827P mutant were analyzed by the CABS-FLEX server (http://biocomp.chem.uw.edu.pl/CABSflex/) (62). DOCK8 fragment 1792-1879 from the 3vhl structure was used in the simulation. For each simulation, 12 clustered structure models were obtained and analyzed through residue fluctuation and dynamic movements. Coot (63) and Pymol (64) were used in structural visualization and presentation.

DOCK8 guanine nucleotide exchange activity assay. The DHR2 containing C-terminal regions of WT or mutant DOCK8 (aa 1639-2071, WT, or S1827P) fused to Gaussia luciferase secretory peptide were cloned into the pCDNA6/V5-His (Invitrogen, Thermo Fisher Scientific) mammalian expression vector and expressed in HEK293 cells. The Histagged recombinant proteins were purified using a TALON Gravity Column Purification Kit (Clontech). Nucleotide exchange was determined using a fluorescence-based RhoGEF exchange activity assay kit according to the manufacturer's instructions (Cytoskeleton). Briefly, CDC42GDP was mixed with MANT-GTP [2'-/3'-O-( $N^{\prime}$-methylanthraniloyl) guanosine-5'-O-triphosphate, trisodium salt] in the exchange buffer and brought to room temperature. The DHR2 domains of WT or S1827P mouse DOCK $8(5 \mu \mathrm{M})$ were added to the mixture, and the fluorescence (excitation $[\mathrm{ex}]=360 \mathrm{~nm}$ and emission $[\mathrm{em}]=440 \mathrm{~nm}$ ) was measured over time using a spectrofluorometer (LS50B; PerkinElmer).

EM. Glass coverslips were coated with $1 \mathrm{mg} / \mathrm{ml}$ poly-L-lysine (Sigma-Aldrich) for 1 hour at room temperature, followed by $10 \mu \mathrm{g} / \mathrm{ml}$ rat anti-mouse CD3 mAb OKT3 (Serotec) in a humidified chamber overnight at $4^{\circ} \mathrm{C}$. T cells were adhered to anti-CD3-coated coverslips by centrifugation at $280 \times g$ for 5 minutes at $4^{\circ} \mathrm{C}$, stimulated for 30 minutes at $37^{\circ} \mathrm{C}$, and mechanically unroofed with poly-L-lysine-coated coverslips in PHEM buffer (60 mM PIPES, 25 mM HEPES, 10 mM EGTA, 2 $\mathrm{mM} \mathrm{MgCl}, \mathrm{pH}$ 6.9) containing $1 \mu \mathrm{M}$ phallacidin and protease inhibitors. Unroofed cells were briefly washed in PHEM buffer and fixed with $1 \%$ glutaraldehyde in PHEM buffer for 10 minutes. The coverslips were washed extensively in distilled water, rapidly frozen on a helium-cooled copper block, freeze dried in a Cressington CFE-50 apparatus (Cressington Scientific Instruments) at $-90^{\circ} \mathrm{C}$, and rotary coated with $1.5 \mathrm{~nm}$ tantalum/tungsten at a $25^{\circ}$ angle and $4 \mathrm{~nm}$ carbon at $90^{\circ}$ without rotation. Specimens were examined and photographed in a JEOL 1200 EX electron microscope using a 100-kV accelerating voltage.

Determination of cellular F-actin content. Purified splenic $\mathrm{CD}^{+}$ $\mathrm{T}$ cells were rested in RPMI-1640 for 2 hours on ice. Cells were then incubated with $10 \mu \mathrm{g} / \mathrm{ml}$ rat anti-mouse CD3 mAb KT3 (Serotec) for 30 minutes on ice and stimulated by cross-linking with $20 \mu \mathrm{g} / \mathrm{ml}$ $\mathrm{F}\left(\mathrm{ab}^{\prime}\right)_{2}$ goat anti-rat IgG secondary Ab (Jackson ImmunoResearch Laboratories) for the times indicated in the figure at $37^{\circ} \mathrm{C}$. Cells were fixed in $4 \%$ formaldehyde, washed, and permeabilized with the BD Cytofix/Cytoperm Kit (BD Biosciences). F-actin was stained with FITC-labeled phalloidin (Sigma-Aldrich), and F-actin content was measured with a BD LSRFortessa cell analyzer.

Immune synapse formation, actin foci formation, and CasL phosphorylation. $\mathrm{CD}^{+} \mathrm{T}$ cells freshly isolated from WT, Dock8 ${ }^{--}$, and Dock8 $8^{\text {pripri }}$ mice were incubated in glass chambers (MatTek) precoated with 10 $\mu \mathrm{g} / \mathrm{ml}$ anti-CD3 (2C11) and $1 \mu \mathrm{g} / \mathrm{ml}$ ICAM-1 (extracellular fragment) for 5 minutes at $37^{\circ} \mathrm{C}(6)$. Cells were then fixed using PHEM buffer at $37^{\circ} \mathrm{C}$, permeabilized (0.1\% Triton-X 100, 5 minutes), and stained with Alexa 568-phalloidin (Life Technologies, Thermo Fisher Scientific) and anti-p130Cas (pY165) phospho-specific Ab (Cell Signaling Tech- nology) overnight, followed by incubation with Alexa Fluoro 647-donkey anti-rabbit secondary $\mathrm{Ab}$ for 1 hour. Cells were then imaged using total internal reflection fluorescence (TIRF) microscopy using a Nikon Eclipse Ti microscope equipped with a 100 $\times 1.49$ NA TIRF objective and an AndorDU897 back-illuminated EMCCD camera. The acquired images were analyzed using ImageJ. For the assessment of "foci" actin features within the overall polymerized F-actin network, phalloidin images were processed further: raw phalloidin (actin) images were subjected to a 1.6- $\times 1$.6-micron rolling box high-pass filter, and the resultant high-pass filter image was subtracted from the original raw image, as described previously (6). The final subtracted images were used for actin foci measurements. The intensities of actin foci and p-CasL as well as the synapse areas were measured using ROI tools in Imagej; the measured values were then analyzed for statistical significance as well as plotted using GraphPad Prism (GraphPad Software).

For $\mathrm{T}$ cell-endothelial monolayer assays, the bEnd3 cell line (ATCC), which constitutively expresses ICAM-1 and VCAM-1, was loaded with TSST- 1 and SEB ( $2 \mu \mathrm{g} / \mathrm{ml}$ each) for 1 hour, washed, and incubated with $\mathrm{CD}^{+} \mathrm{T}$ cells derived from WT, Dock8 ${ }^{-/}$, and Dock8 $8^{\text {pripri }}$ mice for 15 minutes at $37^{\circ} \mathrm{C}$. The cells were fixed using PHEM buffer and processed for immunofluorescence, as described above. Subsequently, cells were imaged using a spinning-disc confocal microscope, and a maximum intensity projection encompassing 1 micron at the cell-cell conjugate interface was analyzed for F-actin foci and pCasL levels.

$T$ cell adhesion and transmigration under defined laminar shear flow conditions in vitro. Live-cell imaging of leukocyte adhesion was recorded by a video camera coupled to a Nikon TE2000 inverted microscope equipped with a $20 \times / 0.75$ NA phase-contrast objective and VideoLab software (Mitov) $(36,59)$. Briefly, in vitro polarized WT, Dock8 ${ }^{-/}$, and Dock $8^{\text {pri/pri }}$ Th1 cells $\left(5 \times 10^{5}\right.$ in $\left.100 \mu \mathrm{l}\right)$ were suspended in Dulbecco's PBS containing 0.1\% (w/v) BSA and $20 \mathrm{mM}$ HEPES, pH 7.4, and were drawn across immobilized murine E-selectin-Fc (20 $\mu \mathrm{g} / \mathrm{ml})$, ICAM-1Fc $(20 \mu \mathrm{g} / \mathrm{ml})$, and VCAM-1-Fc $(5 \mu \mathrm{g} / \mathrm{ml})$ chimeric proteins (R\&D Systems) initially at a shear stress level of 1.0 dynes $/ \mathrm{cm}^{2}$, and subsequently, the flow rate was reduced at 3 minutes to 0.8 dynes $/ \mathrm{cm}^{2}$ and finally to 0.5 dynes $/ \mathrm{cm}^{2} 3$ minutes later (59). Th1 cell adhesion was determined in 5 separate fields at the last minute of each flow rate and reflects the accumulation of adherent cells over the range of shear stress examined. At the end of the assay, each adherent T cell on ICAM-1 and $250 \mathrm{ng} /$ $\mathrm{ml}$ SDF-1 $\alpha$ was assessed for its ability to spread. Fully spread cells were scored as 2 points, partially spread cells as 1 point, and round, unspread cells scored as 0 points. The sum of scores was divided by the total number of adherent cells to calculate average scores for each condition.

Polarized Th1 cells were drawn across confluent TNF- $\alpha$-activated (100 ng/ml, 5 hours) MHECs grown on glass coverslips at $37^{\circ} \mathrm{C}$ in an in vitro flow chamber at an estimated shear stress level of 0.8 dynes/ $\mathrm{cm}^{2}$ (59). Live-cell imaging of Th1 cell TEM was performed using a digital imaging system coupled to a Nikon Eclipse Ti inverted microscope (Nikon) equipped with a $20 \times / 0.75$ NA DIC objective. Timelapse videos were acquired using MetaMorph software (Molecular Devices). The total number of accumulated Th1 cells was determined by counting total adherent and transmigrated cells per coverslip. The percentage of TEM = total transmigrated leukocytes/(total adhered + transmigrated leukocytes) $\times 100$.

In vivo homing of $T$ cells to LNs. In vivo homing of $\mathrm{T}$ cells was performed as previously described (7). T cells were purified from spleen by negative selection using a Pan T Cell Isolation Kit II (Miltenyi Bio- 
tec). WT T cells were labeled with $20 \mu \mathrm{g} / \mathrm{ml}$ Alexa Fluor 555 carboxylic acid succinimidyl ester (Life Technologies, Thermo Fisher Scientific) or Alexa Fluor 488 carboxylic acid succinimidyl ester (Life Technologies, Thermo Fisher Scientific) for 15 minutes at $37^{\circ} \mathrm{C}$. Dock8 $8^{-/}$and Dock $8^{\text {pri } / \text { pri }}$ T cells were labeled with Alexa Fluor 488. Labeled cells were then centrifuged, washed, and suspended in RPMI-1640. A total of $10^{7}$ Alexa Fluor 555-labeled WT T cells were mixed with an equal number of either Alexa Fluor 488-labeled WT, Dock8 ${ }^{-/}$, or Dock8 ${ }^{\text {ri }} /$ pri $\mathrm{T}$ cells. Cells were injected i.v. into WT recipient mice. After 1 hour, the mice were sacrificed, and LNs were harvested. Single-cell suspensions were analyzed by flow cytometry, and the percentages of Alexa Fluor 488and Alexa Fluor 555-labeled cells were determined. The T cell homing index was calculated as the ratio of Alexa Fluor 488-labeled cells to Alexa Fluor 555-labeled cells and divided by the ratio of WT to WT cells. To stain for cell death markers, cells were incubated with fixable viability dye eFluor 780 (eBioscience) for 30 minutes at $4^{\circ} \mathrm{C}$, followed by APC-conjugated annexin V (eBioscience) for 15 minutes at room temperature. The percentage of annexin $\mathrm{V}^{+}$(apoptotic), eFluor $780^{+}$ (dead), and eFluor 780- live cells was calculated using FlowJo software.

Statistics. Statistical analysis of the data using 2-tailed Student's $t$ test or 2-way ANOVA for multiple groups was performed with GraphPad Prism (GraphPad Software version 7.01). A $P$ value of less than 0.05 was considered significant.
Study approval. All mouse studies were approved by IACUC of Boston Children's Hospital. All human participants gave written informed consent to participate in a research protocol approved by the Committee on Clinical Investigation at Boston Children's Hospital.

\section{Author contributions}

EJ, MH, MT, ML, SK, NR, SU, VA, and JH performed the experiments and analyzed the data. QQ and HW did the molecular modeling. EJ, MJM, KLR, and CCG generated the mutated mice. WAH provided patients' samples. DC generated the CSAb. JH, DJI, FWL, and RSG designed and supervised the research. EJ, MH, and RSG wrote the manuscript.

\section{Acknowledgments}

This study was supported by the US Public Health Service (USPHS) grant RO1AI114588 (to RSG), K08AI114968 (to EJ), and by National Health and Medical Research Council Project Grant GNT1022922 (to KLR).

Address correspondence to: Raif S. Geha, Boston Children's Hospital, Division of Immunology, One Blackfan Circle, Boston, Massachusetts 02115, USA. Phone: 617.919.2482; E-mail: raif.geha@ childrens.harvard.edu.
1. Masopust D, Schenkel JM. The integration of T cell migration, differentiation and function. Nat Rev Immunol. 2013;13(5):309-320.

2. Massaad MJ, Ramesh N, Geha RS. WiskottAldrich syndrome: a comprehensive review. Ann N Y Acad Sci. 2013;1285:26-43.

3. Abdul-Manan N, et al. Structure of Cdc42 in complex with the GTPase-binding domain of the 'Wiskott-Aldrich syndrome' protein. Nature. 1999;399(6734):379-383.

4. Carlier MF, Ducruix A, Pantaloni D. Signalling to actin: the Cdc42-N-WASP-Arp2/3 connection. Chem Biol. 1999;6(9):R235-R240.

5. Rohatgi R, Nollau P, Ho HY, Kirschner MW, Mayer BJ. Nck and phosphatidylinositol 4,5-bisphosphate synergistically activate actin polymerization through the N-WASP-Arp2/3 pathway. J Biol Chem. 2001;276(28):26448-26452.

6. Kumari S, et al. Actin foci facilitate activation of the phospholipase $\mathrm{C}-\gamma$ in primary $\mathrm{T}$ lymphocytes via the WASP pathway. Elife. 2015;4.

7. Massaad MJ, et al. Binding of WIP to actin is essential for $\mathrm{T}$ cell actin cytoskeleton integrity and tissue homing. Mol Cell Biol. 2014;34(23):4343-4354.

8. Meller N, Merlot S, Guda C. CZH proteins: a new family of Rho-GEFs. J Cell Sci. 2005; 118(Pt 21):4937-4946.

9. Côté JF, Vuori K. GEF what? Dock180 and related proteins help Rac to polarize cells in new ways. Trends Cell Biol. 2007;17(8):383-393.

10. Randall KL, et al. DOCK8 deficiency impairs CD8 T cell survival and function in humans and mice. J Exp Med. 2011;208(11):2305-2320.

11. Randall KL, et al. Dock8 mutations cripple B cell immunological synapses, germinal centers and long-lived antibody production. Nat Immunol. 2009;10(12):1283-1291.

12. Mizesko MC, et al. Defective actin accumulation impairs human natural killer cell function in patients with dedicator of cytokinesis 8 deficiency. J Allergy Clin Immunol. 2013;131(3):840-848.

13. Zhang Q, et al. DOCK8 regulates lymphocyte shape integrity for skin antiviral immunity. J Exp Med. 2014;211(13):2549-2566.

14. Engelhardt KR, et al. Large deletions and point mutations involving the dedicator of cytokinesis 8 (DOCK8) in the autosomal-recessive form of hyper-IgE syndrome. J Allergy Clin Immunol. 2009;124(6):1289-302.e4.

15. Ochs HD, Thrasher AJ. The WiskottAldrich syndrome. J Allergy Clin Immunol. 2006;117(4):725-738; quiz 739.

16. Zhang Q, et al. Combined immunodeficiency associated with DOCK8 mutations. $N$ Engl JMed. 2009;361(21):2046-2055.

17. Harada Y, et al. DOCK8 is a Cdc 42 activator critical for interstitial dendritic cell migration during immune responses. Blood. 2012;119(19):4451-4461.

18. Ham H, et al. Dedicator of cytokinesis 8 interacts with talin and Wiskott-Aldrich syndrome protein to regulate NK cell cytotoxicity. JImmunol. 2013;190(7):3661-3669.

19. Jabara HH, et al. DOCK8 functions as an adaptor that links TLR-MyD88 signaling to B cell activation. Nat Immunol. 2012;13(6):612-620.

20. Sasahara Y, et al. Mechanism of recruitment of WASP to the immunological synapse and of its activation following TCR ligation. Mol Cell. 2002;10(6):1269-1281.

21. de la Fuente MA, et al. WIP is a chaperone for Wiskott-Aldrich syndrome protein (WASP). Proc Natl Acad Sci US A. 2007;104(3):926-931.

22. Koduru S, Massaad M, Wilbur C, Kumar L, Geha $\mathrm{R}$, Ramesh N. A novel anti-WIP monoclonal antibody detects an isoform of WIP that lacks the WASP binding domain. Biochem Biophys Res Commun. 2007;353(4):875-881.

23. Park H, Cox D. Cdc42 regulates Fc gamma recep- tor-mediated phagocytosis through the activation and phosphorylation of Wiskott-Aldrich syndrome protein (WASP) and neural-WASP. $\mathrm{Mol}$ Biol Cell. 2009;20(21):4500-4508.

24. Zeng R, et al. SLP-76 coordinates Nck-dependent Wiskott-Aldrich syndrome protein recruitment with Vav-1/Cdc42-dependent Wiskott-Aldrich syndrome protein activation at the T cell-APC contact site. JImmunol. 2003;171(3):1360-1368.

25. Rohatgi R, Ho HY, Kirschner MW. Mechanism of N-WASP activation by CDC42 and phosphatidylinositol 4, 5-bisphosphate. JCell Biol. 2000;150(6):1299-1310.

26. Higgs HN, Pollard TD. Activation by Cdc42 and PIP(2) of Wiskott-Aldrich syndrome protein (WASp) stimulates actin nucleation by Arp2/3 complex. J Cell Biol. 2000;150(6):1311-1320.

27. Ramesh N, Geha R. Recent advances in the biology of WASP and WIP. Immunol Res. 2009;44(1-3):99-111.

28. Tskvitaria-Fuller I, Seth A, Mistry N, Gu H, Rosen MK, Wülfing C. Specific patterns of Cdc42 activity are related to distinct elements of $\mathrm{T}$ cell polarization. J Immunol. 2006;177(3):1708-1720.

29. Salazar-Fontana LI, Barr V, Samelson LE, Bierer BE. CD28 engagement promotes actin polymerization through the activation of the small Rho GTPase Cdc42 in human T cells. JImmunol. 2003;171(5):2225-2232.

30. Haddad E, et al. The interaction between Cdc42 and WASP is required for SDF-1-induced T-lymphocyte chemotaxis. Blood. 2001;97(1):33-38.

31. Chemin K, et al. Cytokine secretion by CD4+ T cells at the immunological synapse requires Cdc42-dependent local actin remodeling but not microtubule organizing center polarity. JImmunol. 2012;189(5):2159-2168.

32. Matalon O, Reicher B, Barda-Saad M. WiskottAldrich syndrome protein--dynamic regulation 
of actin homeostasis: from activation through function and signal termination in T lymphocytes. Immunol Rev. 2013;256(1):10-29.

33. Gomez TS, Billadeau DD. T cell activation and the cytoskeleton: you can't have one without the other. Adv Immunol. 2008;97:1-64.

34. Lambe T, et al. DOCK8 is essential for T-cell survival and the maintenance of CD8+ T-cell memory. Eur JImmunol. 2011;41(12):3423-3435.

35. Muller WA. Mechanisms of leukocyte transendothelial migration. Annu Rev Pathol. 2011;6:323-344.

36. Azcutia V, et al. CD47 plays a critical role in T-cell recruitment by regulation of LFA- 1 and VLA-4 integrin adhesive functions. Mol Biol Cell. 2013;24(21):3358-3368.

37. Förster R, Braun A, Worbs T. Lymph node homing of $\mathrm{T}$ cells and dendritic cells via afferent lymphatics. Trends Immunol. 2012;33(6):271-280.

38. Mou F, et al. The Mst1 and Mst2 kinases control activation of rho family GTPases and thymic egress of mature thymocytes. J Exp Med. 2012;209(4):741-759.

39. Choi J, et al. Mst1-FoxO signaling protects Naïve $\mathrm{T}$ lymphocytes from cellular oxidative stress in mice. PLoS ONE. 2009;4(11):e8011.

40. Antón IM, et al. WIP deficiency reveals a differential role for WIP and the actin cytoskeleton in T and B cell activation. Immunity. 2002;16(2):193-204.

41. Le Bras S, et al. WIP is critical for T cell responsiveness to IL-2. Proc Natl Acad Sci U S A. 2009;106(18):7519-7524.

42. Uruno T, et al. Activation of Arp $2 / 3$ complexmediated actin polymerization by cortactin. Nat Cell Biol. 2001;3(3):259-266.

43. Suetsugu S, Miki H, Yamaguchi H, Obinata T, Takenawa T. Enhancement of branching efficiency by the actin filament-binding activity of N-WASP/WAVE2. J Cell Sci. 2001; 114(Pt 24):4533-4542.
44. Cannon JL, Burkhardt JK. Differential roles for Wiskott-Aldrich syndrome protein in immune synapse formation and IL-2 production. J Immunol. 2004;173(3):1658-1662.

45. Calvez R, Lafouresse F, De Meester J, Galy A, Valitutti S, Dupré L. The Wiskott-Aldrich syndrome protein permits assembly of a focused immunological synapse enabling sustained T-cell receptor signaling. Haematologica. 2011;96(10):1415-1423.

46. Dovas A, Cox D. Regulation of WASp by phosphorylation: Activation or other functions? Commun Integr Biol. 2010;3(2):101-105.

47. Takenawa T, Suetsugu S. The WASP-WAVE protein network: connecting the membrane to the cytoskeleton. Nat Rev Mol Cell Biol. 2007;8(1):37-48.

48. Lafouresse F, Vasconcelos Z, Cotta-de-Almeida $\mathrm{V}$, Dupré L. Actin cytoskeleton control of the comings and goings of T lymphocytes. Tissue Antigens. 2013;82(5):301-311.

49. Lim YC, et al. Alpha4beta1-integrin activation is necessary for high-efficiency T-cell subset interactions with VCAM-1 under flow. Microcirculation. 2000;7(3):201-214.

50. Ham H, et al. Dedicator of cytokinesis 8 interacts with talin and Wiskott-Aldrich syndrome protein to regulate NK cell cytotoxicity. J Immunol. 2013;190(7):3661-3669.

51. Duong LT, Rodan GA. PYK2 is an adhesion kinase in macrophages, localized in podosomes and activated by beta(2)-integrin ligation. Cell Motil Cytoskeleton. 2000;47(3):174-188.

52. Bate N, et al. Talin contains a C-terminal calpain2 cleavage site important in focal adhesion dynamics. PLoS One. 2012;7(4):e34461.

53. Massaad MJ, et al. A peptide derived from the Wiskott-Aldrich syndrome (WAS) proteininteracting protein (WIP) restores WAS protein level and actin cytoskeleton reorganization in lymphocytes from patients with WAS mutations that disrupt WIP binding. JAllergy Clin Immunol. 2011;127(4):998-1005.e1.

54. Carman CV, et al. Transcellular diapedesis is initiated by invasive podosomes. Immunity. 2007;26(6):784-797.

55. Gallego MD, de la Fuente MA, Anton IM, Snapper S, Fuhlbrigge R, Geha RS. WIP and WASP play complementary roles in $\mathrm{T}$ cell homing and chemotaxis to SDF-1alpha. Int Immunol. 2006;18(2):221-232.

56. Hogg N, Patzak I, Willenbrock F. The insider's guide to leukocyte integrin signalling and function. Nat Rev Immunol. 2011;11(6):416-426.

57. Snapper SB, et al. Wiskott-Aldrich syndrome protein-deficient mice reveal a role for WASP in T but not B cell activation. Immunity. 1998;9(1):81-91.

58. Minowada J, et al. Characteristics of 27 human T-cell leukemia cell lines with/without T-cell receptors of T3-Ti alpha beta or T3-Ti gamma delta complex. Haematol Blood Transfus. 1989;32:233-236.

59. Alcaide P, et al. Difference in Th1 and Th17 lymphocyte adhesion to endothelium. JImmunol. 2012;188(3):1421-1430.

60. Sanjabi S, et al. A c-Rel subdomain responsible for enhanced DNA-binding affinity and selective gene activation. Genes Dev. 2005;19(18):2138-2151.

61. Sukumvanich P, et al. Cellular localization of activated N-WASP using a conformation-sensitive antibody. Cell Motil Cytoskeleton. 2004;59(2):141-152.

62. Jamroz M, Kolinski A, Kmiecik S. CABS-flex: Server for fast simulation of protein structure fluctuations. Nucleic Acids Res. 2013;41(Web Server issue):W427-W431.

63. Emsley P, Cowtan K. Coot: model-building tools for molecular graphics. Acta Crystallogr D Biol Crystallogr. 2004;60(Pt 12 Pt 1):2126-2132.

64. Delano WL. The PyMol Molecular Graphics System. PyMol. http://www.pymol.org. Accessed July $29,2016$. 